\title{
LOS NIÑOS DE EL SALVADOR Necesidades educativas. Prácticas educativas
}

\author{
Luis Pérez Miguel*
}

Este artfculo presenta algunos resultados de la investigación realizada entre Septiembre y Diciembre de 1994 a solicitud del Comité Interinstitucional, entidad integrada por OG's, ONG's y Universidades privadas de El Salvador que trabajan en programas de atención al menor, $y$ que tuvo financiamiento de UNICEF. No hemos incluldo en este resumen los programas gubernamentales ni otros aspectos del estudio dado que excede las posibilidades del presente artículo.

\section{Aclarando conceptos}

$\mathrm{F}^{1}$ propósito de este apartado es contribuir a la claridad concepL tual de las personas dedicadas y/o interesadas en el tema de la niñez y enfocar la atención infantil en una perspectiva más amplia, ligada al desarrollo humano $y$, sobre todo, a una mayor calidad de vida.

\section{Calidad de vida, necesidades básicas y desarrollo humano}

Dlanteado en términos sencillos, el desarrollo humano se refiere 1 al proceso de cambio por el que las personas pueden desempeñar actividades siempre más complejas. El desarrollo incluye una dimensión física (la capacidad para moverse y coordinar), una dimensión intelectual (la capacidad para pensar y razonar), una dimensión social (la capacidad para relacionarse con otros) y una

* Profesor investigador del Departamento de Educación de la UCA. 
dimensión emocional (autoconfianza y capacidad para sentir).

Aparte de los requerimientos de alimento, amparo, atención en salud y protección, los niños pequeños tienen necesidades psicológicas y sociales básicas para su desarrollo, entre las que se incluyen:

- necesidad de amor y afecto;

- necesidad de una interacción (tanto brindando estímulos al niño como reaccionando ante él);

- necesidad de una consistencia y previsibilidad en el ambiente de atención al niño;

- necesidad de explorar y descubrir, pero cada uno de ellos poseen un conjunto de necesidades determinadas por sus propias características genéticas, por las condiciones inmediatas de la familia, que satisfacen (o no) algunas de las necesidades básicas, y por las condiciones en la comunidad y en la sociedad en general. Tanto las circunstancias familiares como las de la comunidad establecen objetivos e imponen límites al niño que inciden en su desarrollo.

El aprendizaje básico empieza en el nacimiento (y hay determinantes significativos del aprendizaje que pueden tener su origen antes del nacimiento) y no en el momento de iniciar las actividades de aprendizaje formales, por lo que en los programas de salud, nutrición y desarrollo social es preciso mirar más allá de los beneficios inmediatos y tener presentes los efectos positivos a largo plazo sobre el aprendizaje. 2

Por calidad [de vida o de educación] entendemos un proceso por medio del cual se sale de una situación dada [vital o educativa] hacia otra situación ideal. En este sentido, la calidad es una categoría dinámica, como realidad y como concepto relativo; es un proceso que se construye; se obtiene en la medida que se sale de la situación actual para llegar a la situación ideal. 3

\section{Calidad de vida, necesidades básicas y educación}

I as poblaciones marginadas dependen de sus conocimientos y su Lcapacidad de resolver problemas para hacer frente a las dificultades creadas por las guerras, los conflictos civiles y la delincuencia, así como la discriminación... Un aumento del nivel básico 
de aprendizaje contribuye a mitigar las situaciones de desventaja $y$, por consiguiente, a disminuir las disparidades sociales. La satisfacción de necesidades básicas de aprendizaje de las poblaciones marginadas no resolverá sus problemas, pero debe ser parte de la solución. Se necesitan sobre todo formas no convencionales de educación básica para aquellos cuyas vidas se han visto conmovidas por fuerzas que escapan a su control.4

Existen pruebas cada vez más convincentes de que la salud, la nutrición y los procesos psicosociales interactúan e influyen así sobre la posibilidad de supervivencia y desarrollo en los primeros años de la vida. ... Los programas para la primera infancia pueden tener un importante efecto equiparador al reducir las disparidades de los procesos escolares ulteriores. Pero mientras dichos programas estén reservados exclusivamente a los grupos sociales de mayores ingresos, pueden otorgar aún más ventajas a esos grupos y acrecentar así las desigualdades en los progresos de los alumnos.5

\section{Necesidades básicas de aprendizaje}

T as necesidades básicas de aprendizaje comprenden tanto ins Ltrumentos fundamentales de aprendizaje (alfabetización, expresión oral, aritmética y resolución de problemas), como el contenido básico de los aprendizajes (conocimientos, capacidades, valores y actitudes) que necesitan los seres humanos para poder sobrevivir, desarrollar plenamente sus posibilidades, vivir y trabajar dignamente, participar plenamente en el desarrollo, mejorar su calidad de vida, tomar decisiones fundamentales y seguir aprendiendo. El alcance de las necesidades básicas de aprendizaje y la manera de satisfacerlas varía según cada país y cada cultura e, inevitablemente, cambia con el paso del tiempo.6

Con un mayor nivel de conocimientos, las personas y los grupos están en mejores condiciones de obtener un sustento del entomo, de participar efectivamente en la sociedad, de enfrentar desafíos, de idear nuevas soluciones y de mejorar así el mundo. El aprendizaje es un catalizador del proceso de desarrollo, mientras que la falta de oportunidades de aprendizaje limita la capacidad de las personas y de las sociedades de crear desarrollo o de beneficiarse de él.7 
Del número creciente de estudios e informes sobre programas específicos de desarrollo de la primera infancia, se han puesto de manifiesto dos consecuencias importantes de los programas de este tipo para satisfacer las necesidades básicas de aprendizaje: la primera es que el cuidado del desarrollo físico y psicosocial de los niños a menudo acrecienta su capacidad para aprovechar la escolarización, lo que a su vez aumenta la eficacia del sistema educativo. La segunda es que los efectos positivos de los programas de desarrollo para la primera infancia sobre el rendimiento escolar son a menudo mayores para las niñas que para los niños y para alumnos que pertenecen a grupos sociales desventajados, en comparación con niños de hogares más ricos. 8

\section{Supervivencia del niño}

Trónicamente, el concepto de supervivencia a menudo se define Len forma negativa: sobrevivir es no morir. Sin embargo, puede considerarse que la supervivencia es más que la simple prevención de la muerte. Vivir es un proceso cuyo fin no es sólo la supervivencia, sino también la salud, el bienestar físico, mental y emocional. Los niños que sobreviven pueden ser situados en un proceso que va desde las proximidades de la muerte, pasando por la enfermedad, hasta el estado saludable. Por esta razón, el proceso de supervivencia puede considerarse como la búsqueda de un estado saludable...

Aceptar esta reconceptualización positiva exige ir más allá del análisis de las causas de la mortalidad y de los programas para reducirla. Significa que debemos determinar en qué punto se encuentran los niños en el continuo salud-crecimiento-desarrollo, que debemos buscar programas que mejoren su salud, lo que demanda claridad respecto a lo que constituye, en un sentido positivo, moverse en un "estado saludable". 9

\section{Crecimiento}

耳 1 crecimiento es el aumento de tamaño. Las medidas de creci¿miento más utilizadas son el peso y la talla, o ambas. En los últimos años, el énfasis en las normas de crecimiento ha sido desplazado lentamente por la perspectiva de ver el crecimiento como un proceso. El crecimiento constante indica progreso. La falta de 
crecimiento (señalada por la falta de aumento en el peso o la talla, por ejemplo) indica que es necesaria una acción correctiva. Por esta razón, el punto en que se encuentra un niño en la tabla es menos importante que la forma en que se produce el cambio, es decir, se debe determinar si se ha producido un aumento o una reducción en relación con la medición anterior.

Además, el crecimiento físico (y la supervivencia) no dependen únicamente de la calidad y cantidad de alimento que ingiere el niño, sino de la forma en que son asimilados y utilizados por el organismo, y de factores como el buen desarrollo social y psicológico del niño y de la reducción del estress a que se ven sometidos él y la persona encargada de cuidarlo. 10

\section{Desarrollo del niño}

W ientras el crecimiento se describe como un cambio en el ta1 maño, el desarrollo se caracteriza por cambios en la complejidad y la función. Cuando un niño aprende a coordinar la vista con el movimiento de las manos para coger un objeto, está dando señales de desarrollo de una forma compleja de pensamiento, lo cual es independiente del tamaño del niño.

A nivel operativo, podemos definir el desarrollo del niño como un proceso de cambio en el que el niño aprende a dominar niveles cada vez más complejos de movimiento, pensamiento, sentimientos y relación con los demás.

Puede también considerarse como un proceso que tiene varias características:

es multidimensional: incluye las dimensiones física, intelectual, emocional y social;

es integral, los diferentes elementos del desarrollo del niño están interrelacionados y deben ser considerados en su conjunto, los cambios en una dimensión influyen en el desarrollo de las otras;

se produce continuamente, el desarrollo comienza antes del nacimiento y continúa a lo largo de toda la vida. Ver el desarrollo como un proceso continuo significa que el niño siempre se está desarrollando, cualquier cosa que suceda en un momento determinado contribuye a preparar el camino para lo que ocurra en el futuro; 
se produce en un proceso de interacción, el desarrollo ocurre cuando el niño responde a sus ambientes biofísico y social, aprende de ellos e interactúa con ellos. Por ello, el fomento del desarrollo exige algo más que ofrecer un estímulo al niño, también exige respuestas a sus iniciativas. (Myers, 1993, p. 48-51)

\section{Atención del niño}

T a atención se refiere a las acciones que son necesarias para $\perp$ facilitar la supervivencia, el crecimiento y el desarrollo; atender al niño requiere responder a sus necesidades básicas.

Las necesidades básicas de desarrollo transcienden el marco de la protección, la alimentación y el cuidado de la salud para incluir la necesidad de afecto, interacción y estímulo, la seguridad que ofrecen la consistencia, la previsibilidad, y el juego que permite la exploración y el descubrimiento. Estas necesidades se encuentran presentes al mismo tiempo. Un ambiente que ofrezca apoyo deberá responder a todas ellas.

Como mínimo, se deben tener en cuenta las siguientes actividades de atención al niño:

brindarle seguridad
darle un techo
vestirlo
alimentarlo
bañarlo
supervisar su aseo
preservar su salud y cuidarlo si se enferma
darle afecto y confianza
interactuar con él y estimularlo
jugar con él
fomentar el proceso de socialización del niño.

Definir la atención del niño de esta forma significa que los programas de atención y de desarrollo deben ser lo mismo.

\section{Educación pre-escolar}

Se utiliza generalmente para referirse a la franja inmediatamen 
mayor edad (4 a 6 ó 7 años) y entendida fundamentalmente como una educación cuya función prioritaria es "preparar al niño para la escuela".

Este "preparar" es entendido de maneras distintas: para las versiones más escolarizantes de la educación pre-escolar, ésta termina siendo un primer grado anticipado en el que los niños son introducidos de forma sistemática al aprendizaje de la lectura y la escritura, el cálculo y otras áreas de conocimiento típicamente escolares, así como a las normas y rituales con que habrán de convivir y que deberán aceptar en la escuela.

\section{Educación inicial}

Guele diferenciarse del término educación pre-escolar, siendo por - lo general entendido de manera más abarcativa, en la medida que incluye a la educación pre-escolar (escolarizante o no), pero no se limita a ésta.

En los últimos tiempos, algunos vienen utilizando el término educación inicial para hacer referencia a una nueva visión y a una nueva corriente de pensamiento que aspira a replantear la orientación convencional de la educación de los niños pequeños $\mathrm{y}$, en particular, de la educación preescolar. Afirma el sentido propio y autónomo que tiene la educación inicial por sí misma en función de las necesidades de desarrollo del niño pequeño.

Investigaciones y evaluaciones muestran que la educación inicial puede tener un impacto significativo y positivo sobre los niños y sus familias, facilitando la transición entre el hogar y la escuela e incidiendo sobre el aprendizaje y el rendimiento escolares. Según concluyen algunas de dichas investigaciones, tal impacto es mayor y notorio sobre todo en los niños provenientes de familias pobres, para quienes la educación inicial puede servir para compensar carencias y puntos desiguales de partida respecto de otros niños en condiciones más ventajosas. No obstante, según concluyen también varios de dichos estudios, no cualquier tipo de educación inicial consigue tales resultados. La calidad de los programas resulta indispensable.

La UNESCO-OREALC al considerar que la expansión de la educación inicial es uno de los fenómenos recientes más significativos 
de América Latina y El Caribe, señala que ésta sigue centrada en las áreas urbanas y en los grupos de edad más avanzada. Ampliar la cobertura hacia los niños menores de 5 años y atender a las áreas rurales es pues un desafío para esta región.

\section{La vida de los niños}

Tntentamos describir la situación de la niñez salvadoreña basán Ldonos en los derechos señalados en la Convención de los Derechos del Niño, de la que El Salvador es signatario. Cuando al inicio de cada apartado se mencionan "Art." nos referimos a los "artículos" de dicha Convención.

\section{Supervivencia, salud básica y bienestar}

\subsection{El derecho a la vida y la supervivencia}

Los Estados Partes reconocen que todo niño tiene derecho intrínseco a la vida. Los Estados Partes garantizarán en la medida de lo posible la supervivencia y el desarrollo del niño. (Art. 6)

El Salvador ha sido caracterizado por una alta inseguridad alimentaria, fundamentalmente en productos que constituyen la canasta básica. Según la FAO, somos de los países latinoamericanos con peores condiciones respecto a la escasez de alimentos, lo que denota una situación insatisfactoria en cuanto al consumo.

En 1988, el $49.1 \%$ de las familias se encontraban en situación de subalimentación crítica y deficiente. En los menores de 5 años esta cifra sube el $60 \%$, siendo mayor en el área rural. Los niveles de ingesta calórica y de proteínas en familias y niños, demuestra que el consumo está por debajo del $90 \%$ de adecuación. El hierro y la Vitamina A son muy deficientes en la dieta, presentando porcentajes de adecuación por debajo del $50 \% .11$

La deficiencia de vitamina $A$ en menores de 5 años era de un $36 \%$, y entre los niños de 12 a 17 meses el $46 \%$ presentaban deficiencia de vitamina A. En 1991, en el grupo de 12 a 36 meses de edad, el $14,4 \%$ de los niños tiene muy bajo peso.

Diversas investigaciones (FESAL, 1993; ESANES, 1988) han mostrado que existen deficiencias significativas en todos los indicadores 
de estado nutricional, retardo en crecimiento (peso/edad), malnutrición crónica (talla/edad), y malnutrición aguda (peso/talla) en todos los estratos sociales en menores de 5 años.

En el niño menor de 5 años los ciclos de desnutrición tienen como consecuencia posterior un retardo en talla en la población escolar, que afecta a 462,300 niños ( $30 \%$ ), quienes proceden de familias que están impactadas por la subalimentación crónica y desnutrición.12

Por otra parte, la producción alimentaria por persona para el periodo 1987-89 ha decaído en un $10 \%$ en relación al período 1979-81 y según datos del Ministerio de Agricultura y Ganadería para el año agrícola 1994/95 la demanda de maíz superará a la producción en un $43.5 \%$, en el caso del frijol el porcentaje alcanza el $40.7 \%$ y en el del arroz el $53 \% .13$

Según los últimos estudios sobre salud materno infantil realizados en el país (FESAL'93 y ANSAL'94) la "Tasa de Mortalidad Infantil mínima debe oscilar entre 42 y 45 [por 1000] y la máxima podría estar en los $55^{\prime \prime} .14$

Principales causas de mortalidad infantil

\begin{tabular}{|c|c|c|c|c|c|}
\hline & $\begin{array}{l}0-28 \\
\text { días }\end{array}$ & $\begin{array}{l}29 \text { días } \\
1 \text { año }\end{array}$ & $\begin{array}{l}0-1 \\
\text { año }\end{array}$ & $\begin{array}{l}1-4 \\
\text { año }\end{array}$ & $\begin{array}{l}0-4 \\
\text { año }\end{array}$ \\
\hline Bajo peso al nacer o prematurez & $34.2 \%$ & & $18.1 \%$ & & $14.6 \%$ \\
\hline Trauma al nacimiento o axfisia & $17.9 \%$ & & & & \\
\hline Anomalias congénitas & $14.5 \%$ & & & & \\
\hline Deshidratación por diarreas (EDA's) & & $35.6 \%$ & $19.0 \%$ & $24.1 \%$ & $20.0 \%$ \\
\hline Enfermedades respiratorias (IRA's) & & $32.7 \%$ & $16.3 \%$ & $27.8 \%$ & $18.6 \%$ \\
\hline Falla de órganos múltiples (Sepsis) & & $10.6 \%$ & & & \\
\hline Sarampión & & & & $13.0 \%$ & \\
\hline
\end{tabular}

Según este mismo estudio, la alta tasa de mortalidad por infecciones respiratorias (IRA's) y enfermedades diarréicas (EDA's) es el resultado de diversos factores entre los que sobresalen el deficiente servicio de agua y saneamiento, deficiente control prenatal e inadecuada atención del parto, deficiente lactancia materna y prácticas alimetarias, inapropiado manejo de las diarreas y las in- 
fecciones respiratorias, ... es decir, de la pobreza.

\subsection{El derecho al desarrollo y a un adecuado nivel de vida}

Los Estados Partes reconocen el derecho de todo niño a un nivel de vida adecuado para su desarrollo (Art. 27)

Según la Encuesta de Hogares de Propósitos Múltiples del Ministerio de Planificación de 1993, más de la mitad de los hogares salvadoreños (el $57.5 \%$ ) están en situación de pobreza, y el $27 \%$ de ellos en pobreza extrema, es decir, sin lo suficiente para el alimento.

Pero a pesar de que esta situación es de por sí alarmante, la realidad podría ser aún peor, puesto que en el cálculo del dato se han incluído las remesas familiares como nuevo componente de ingreso, y no se ha tenido en cuenta el costo de la canasta básica vigente desde 1991. La divergencia entre la estimación actual de la pobreza y la que surgiría al incorporar la nueva canasta básica y excluir las remesas familiares del ingreso, podrían significar un cambio total en el comportamiento recesivo de la pobreza. 15

Las características de las viviendas reflejan también una situación precaria. Según FESAL'93, a nivel nacional el $56.1 \%$ de las viviendas carece de agua y en la zona rural este porcentaje es del $85.9 \%$. En esta misma zona, el $50.5 \%$ de las viviendas no disponen de energía eléctrica, el $52 \%$ no cuenta con letrinas y el $93.3 \%$ no tiene inodoros (a nivel nacional, el $62.4 \%$ no dispone de ellos). 16

El analfabetismo, a nivel nacional, alcanza el $48 \%$, incluyendo el analfabetismo funcional. Pero en el área rural, dos de cada tres personas mayores de 14 años son analfabetas. Entre el $20 \%$ más pobre de la población, el analfabetismo llega al $72.14 \%$.

\subsection{El derecho a la salud y a los servicios de salud}

Los Estados Partes reconocen el derecho del niño al disfrute del más alto nivel posible de salud y a servicios para el tratamiento de las enfermedades y la rehabilitación de la salud. ... (Art. 24)

Según ANSAL'94, con el actual sistema de salud, uno de cada dos niños de futuras generaciones sufrirá enfermedades vinculadas a la pobreza, las cuales limitarán su desarrollo. 
La provisión de servicios de salud en El Salvador está a cargo del Ministerio de Salud Pública y Asistencia Social que tiene una cobertura aproximada del $\mathbf{8 0} \%$ de la población. El Instituto Salvadoreño del Seguro Social cubre un 10\%, ONG's y Sector Privado un $6 \%$, mientras otras instituciones gubernamentales que tienen sus propios sistemas cubren un $4 \% " .17$

Centroamérica: Gasto en salud como porcentaje del P.N.B. (1990)

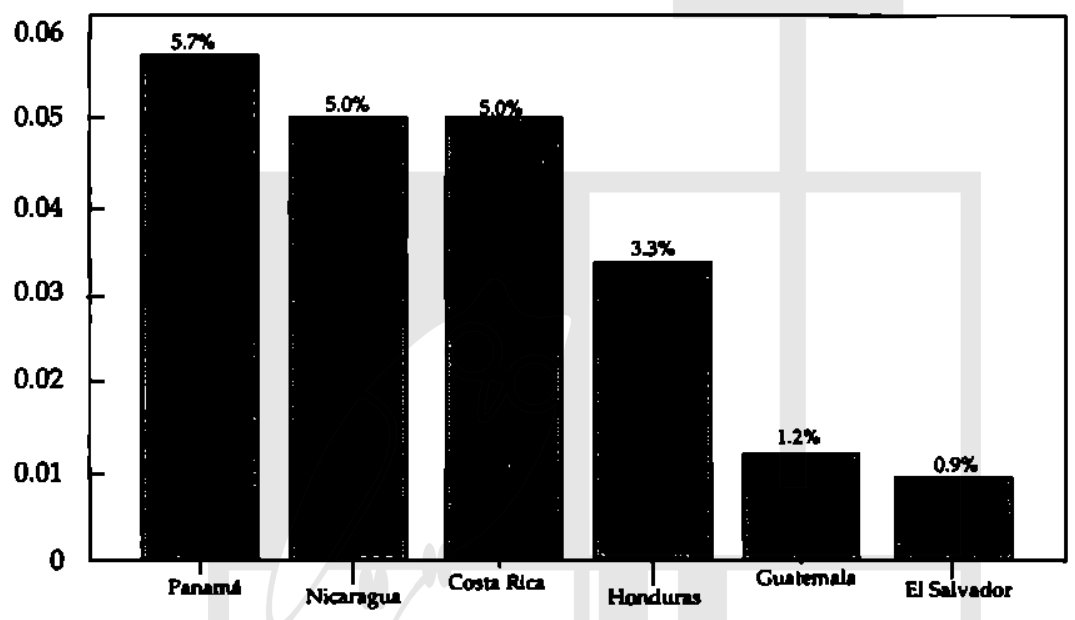

En El Salvador menos de un cuarto de la población está cubiertá por la Seguridad Social, lo que le ubica, de entre veinte países de América Latina, en el lugar número diecisiete, sólo arriba de Honduras, Haiti y República Dominicana, y la alternativa de la privatización no resuelve la brecha de la baja cobertura (5\% de la población total y $14 \%$ de la población económicamente activa) ya que la experiencia ha demostrado la exclusión de la mayoría de la población no asalariada, no formal y sobre todo rural, que no tiene acceso a los programas privados de salud.18 
El Salvador. Gastos de salud

como \% del gasto de gobierno (1975-1992)

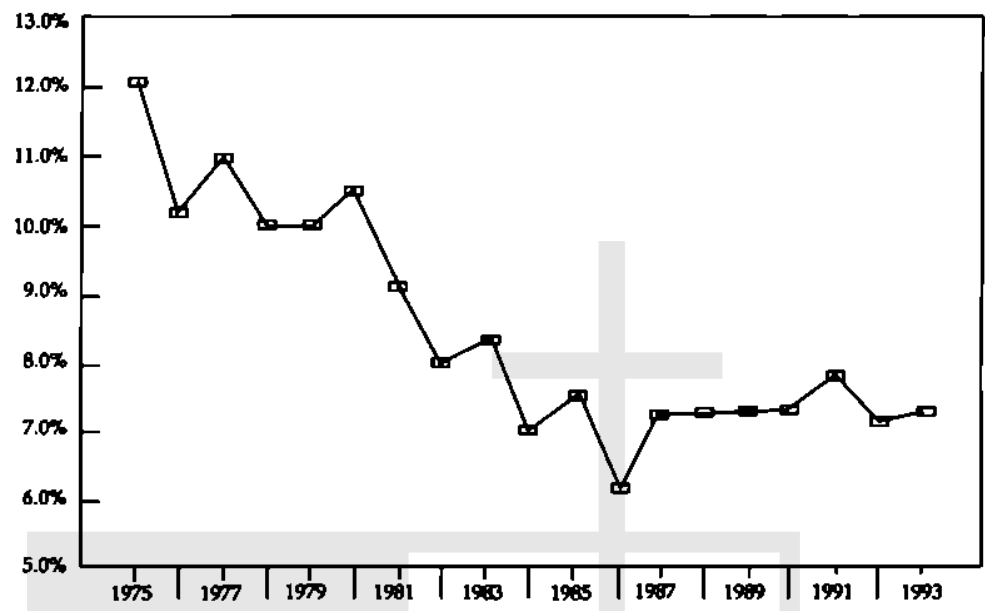

\section{Educación}

\subsection{El derecho a educación gratuita}

Los Estados Partes reconocen el derecho del niño a la educación $y$, a fin que se pueda ejercer progresivamente $y$ en igualdad de oportunidades ese derecho, deberán en particular: a) Implantar la enseñanza primaria obligatoria y gratuita para todos.(Art.28)

Centroamérica. Gasto en educación como porcentaje del P.N.B, (1988)

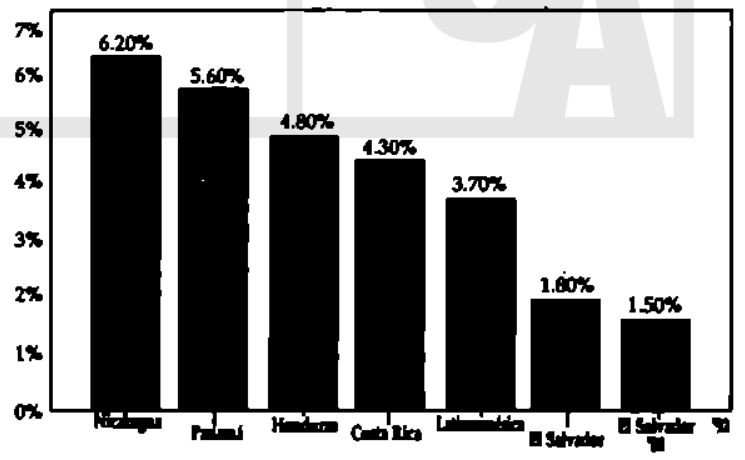


El Salvador es de los países en el mundo con un menor gasto educativo por alumno, a todos los niveles, entre los 6 que menos recursos destinan por alumno de primaria, entre los 9 que menos recursos destinan de secundaria y entre los 32 que menos recursos destinan por alumno de educación superior. Respecto a los países de Centroamérica y el conjunto de países latinoamericanos, la relación es como se aprecia en el gráfico. Según el último diagnóstico de la situación educativa, en 1988, de 120 países, sólo cuatro invertían menos recursos en educación como porcentaje del PNB (Zaire con 1,4\%, Paraguay y República Dominicana con $1,5 \%$ y Haití con 1,6\%). 19

El Salvador. Gasto en educación como \% del gasto de gobierno (1975-1992)

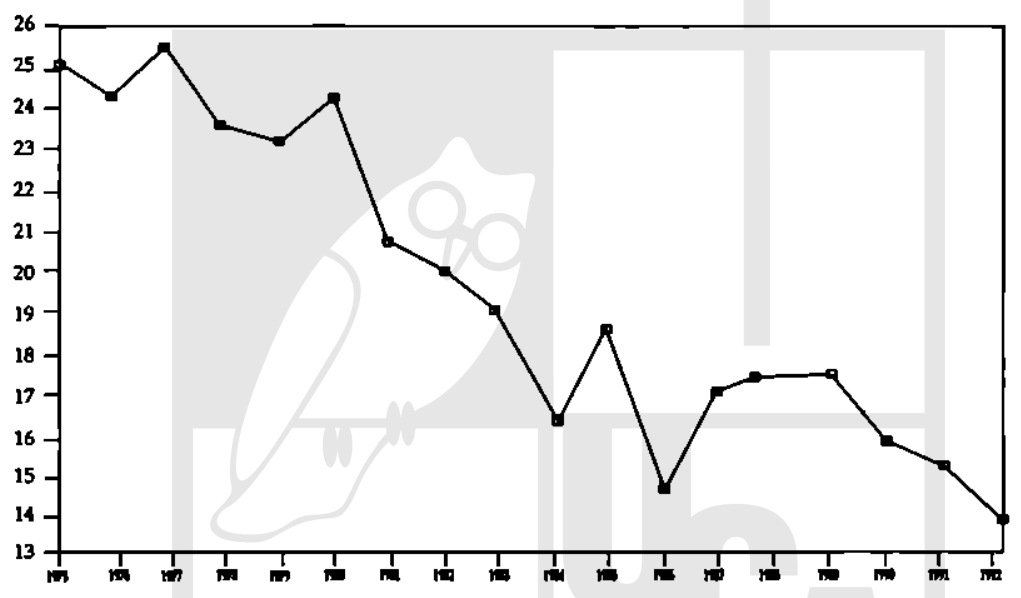

En El Salvador los recursos destinados a financiar la educación de las futuras generaciones han disminuído sistemáticamente durante la última década de guerra. Como porcentaje del Producto Nacional Bruto, el gasto en educación cayó de $3,6 \%$ en 1980 a $1,5 \%$ en 1992. Esto expresa reducciones en el gasto público, pero también reducciones en el esfuerzo destinado al sector educativo dentro del gasto público. En efecto, como porcentaje del total del gasto de gobiemo, el gasto en educación disminuyó de $24 \%$ en 1980 a $13,6 \%$ en 1992. En términos reales, el gasto educativo en 1982 re- 
presentaba $86 \%$ del mismo gasto en 1980 .

En lo que se refiere específicamente a la atención educativa a los menores de 7 años, la distribución de gastos para los diferentes niveles educativos en 1992, muestra que el gasto en parvularia apenas llega al 5\% del presupuesto total, mientras que la educación básica (1o. a 9o. grados) absorbe el $71 \%$.

Gastos por nivel educativo

(\% de gastos en educación, 1992)

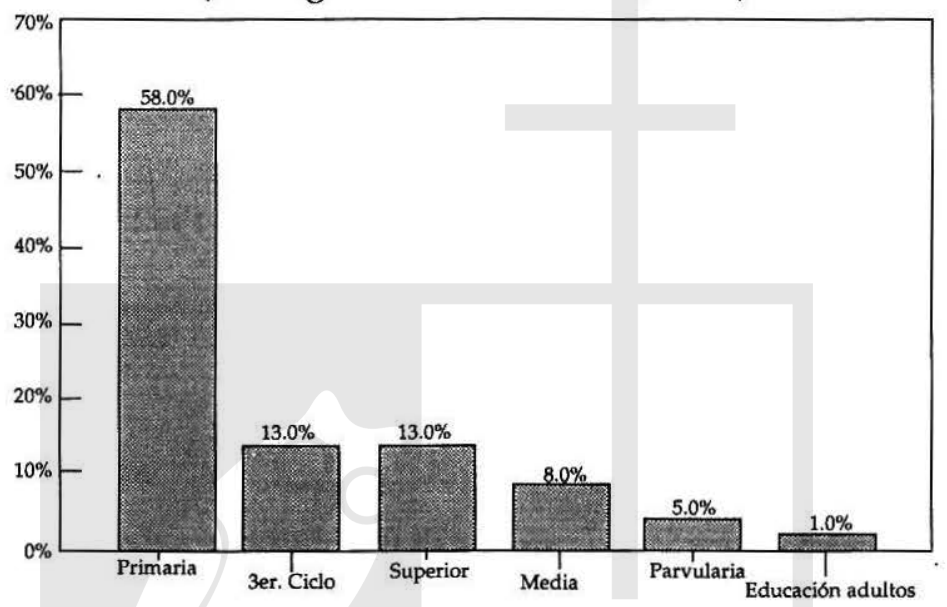

Primera consecuencia de esta asignación de recursos es la cobertura de la educación parvularia. Aunque exite un constante incremento de la matrícula, la población atendida es aún muy poca, como se puede apreciar en los gráficos 6 y 7 , según los cuales apenas uno de cada cuatro niños asiste a la escuela.

Atención educativa de la población de 0 a 3 años (\%)

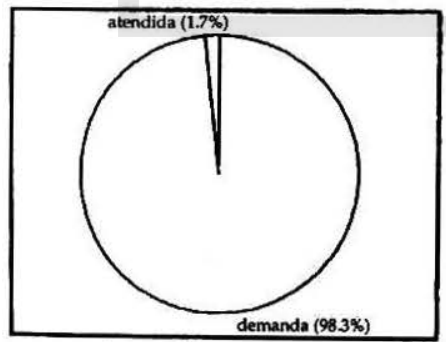

Atención educativa de la población de 4 a 6 años (\%) 
Pero además, esta distribución no es uniforme ni afecta a todos los niños por igual, sino que existe una relación directa entre el nivel educativo de la población y su nivel de ingresos. Mientras entre los más pobre de los pobres (el $20 \%$ de la población de más bajos recursos) sólo siete de cada cien niños tiene la oportunidad de asistir a parvularia, entre los más ricos al menos ocho de cada diez niños tienen la oportunidad de asistir. Y si al nivel económico le añadimos la zona de residencia, la desigualdad crece aún más: a los cuatro años sólo uno de cada cuatro niños que asiste a la escuela vive en la zona rural, y entre los más pobres sólo 3 de cada cien niños de la zona rural asisten a la escuela.

\section{Probabilidad de asistir a parvularia según edad y nivel de ingresos}

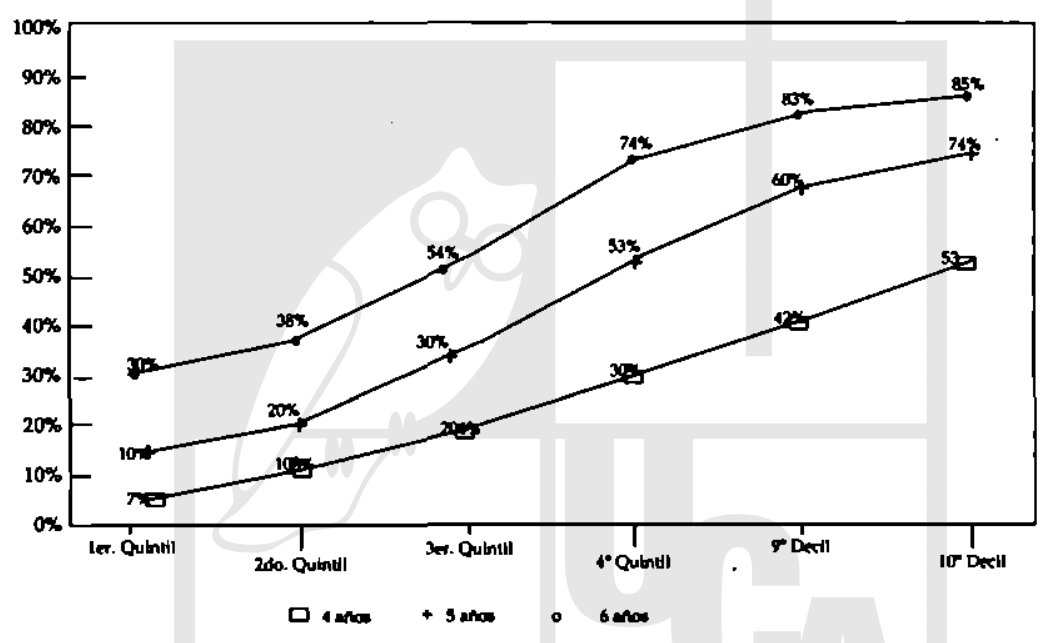

\subsection{El derecho a una educación acorde con la Convención}

Los Estados Partes convienen en que la educación del niño deberá estar encaminada a: a) Desarrollar la personalidad ...; b) Inculcar el respeto de los derechos humanos ...; c) Inculcar el respeto de sus padres, de su propia identidad cultural, ...; d) Preparar al niño para asumir una vida responsable en una sociedad libre ...; e) Inculcar al niño el respeto del medio ambiente natural ...(Art. 29)

En un estudio sobre autoritarismo en el aula realizado por $\mathrm{A}$. Fernández, se destaca que el $95 \%$ de los profesores opinan "que la 
obediencia y el respeto por la autoridad son las principales virtudes que debemos enseñar a los niños". El 93\% de los alumnos opina de igual forma.

Parece ser que tanto la familia como la escuela inculcan en los niños la sumisión y la obediencia como valores sociales principales para sus vidas. Según los resultados, se puede afirmar que los alumnos están asumiendo la sumisión y la obediencia como una característica de su personalidad.20

Esta situación educativa de la niñez no responde al compromiso de una educación acorde con la Convención ni en sus objetivos ni en su contenido. La educación actual no sirve para solucionar los problemas personales, familiares, o profesionales, ni responde a las exigencias del entorno.

Las condiciones de infraestructura y equipamiento en que se encuentran las escuelas ubicadas en las zonas rurales, la labor de muchos maestros y la escasa relación de lo que allí se aprende con la realidad, hace que entre los cuatro y los seis años junto con la falta de recursos, la falta de interés sea uno de los principales motivos de no asistencia a la escuela.

\section{Derecho a la Identidad}

"El niño será inscrito inmediatamente después de su nacimiento $y$ tendrá drerecho desde que nace a un nombre, a adquirir una nacionalidad, ... (Art.7) "Los Estados partes se comprometen a respetar el derecho del niño a preservar su identidad, incluídos la nacionalidad, el nombre y las relaciones familiares de conformidad con la ley sin injerencias ilícitas". (Art.8)

El Artículo 36, inciso 2, de la Constitución Política establece el derecho de toda persona a tener un nombre que la identifique, $y$ el Código Penal (Artículos 272,273 y 274) y la Ley del Nombre de la Persona Natural contienen reglas sobre el respeto relativo a la identidad de los menores y sobre la preservación de la identidad, cuando se trata de cambiar o modificar el nombre, así como en los casos de diversidad de nombres en un individuo.

Sin embargo, nuevamente la realidad no responde a la norma. Las condiciones económicas y sociales en que se desenvuelven las 
familias salvadoreñas, la ineficiencia de la administración pública y el conflicto armado han contribuído a que una buena parte de la población, sobre todo infantil, carezca del oportuno registro de identidad. Esta problemática se hace más evidente en la población desplazada y repatriada.

En una reciente investigación de la Red Salvadoreña de Salud Mental sobre los derechos del niño, en el $29.3 \%$ de los casos consultados se había violado el derecho a la identidad y esta violación, según el status social de los niños, se distribuía de la siguiente manera:

\section{Violación del derecho a la identidad}

\begin{tabular}{|c|c|c|}
\hline Status & Frecuencia & Porcent \\
\hline Marginal & 7 & $14.6 \%$ \\
\hline Desplazado & 8 & $33.3 \%$ \\
\hline Trabajador & 5 & $10.0 \%$ \\
\hline Sector medio & 29 & $55.8 \%$ \\
\hline Víctima represión & 1 & $3.4 \%$ \\
\hline Repatriado & 13 & $26.0 \%$ \\
\hline Repoblador & 10 & $45.5 \%$ \\
\hline Ex-combatiente & 15 & $36.6 \%$ \\
\hline
\end{tabular}

Según los autores, la paradojica situación en la que los niños de los sectores medios aparezcan como los más violentados en sus derechos, se debe al mayor conocimiento que tienen de ellos. Puesto que el estudio se basa en la consulta directa a los menores, el conocimiento o no del derecho respectivo explicaría la apreciación sobre si ha sido o no violado.

\section{Trabajo infantil}

"Los Estados Partes reconocen el derecho del niño a estar protegido contra la explotación económica y contra el desempeño de cualquier trabajo que pueda ser peligroso o entorpecer su educación, ...". (Art. 32) 
Según el Artículo 38, inciso 1, ordinal 10, de la Constitución Política "Los menores de 14 años y los que habiendo cumplido esa edad sigan sometidos a la enseñanza obligatoria en virtud de la ley, no podrán ser ocupados en ninguna clase de trabajo. Pero ... "Podrá autorizarse su ocupación cuando se considere indispensable para la subsistencia de los mismos o de su familia, siempre que ello no le impida cumplir con el mínimo de instrucción obligatoria", las jornadas de los menores de dieciséis años no podrá ser mayor de seis horas diarias y de treinta y cuatro horas semanales, en cualquier clase de trabajo. Se prohíbe el trabajo de los menores de dieciocho años y a las mujeres en labores insalubres o peligrosas. También se prohíbe el trabajo noctumo a los menores de 18 años.

El Código de Trabajo en sus artículos 114 y 116 recoge ampliamante estas disposiciones y añade que en el caso de que el menor trabaje, "el patrono deberá disponer el horario de trabajo de manera que los menores puedan asistir a la escuela en que reciben su enseñanza".

El "Análisis de situación de la infancia y de la mujer en El Salvador. 1991", de UNICEF, citando al Ministerio de Trabajo, señala que en 1990 sólo 7,679 menores solicitaron autorización para el trabajo. De éstos, 4, 238 eran varones y 3,435 mujeres. Las edades de estos menores oscilaron entre los 16 y los 18 años y el tipo de empresas en las que se incorporaron fueron talleres de mecánica para los varones y de costura para las mujeres, y en menor medidad como trabajadores de restaurantes, hoteles y otras actividades del sector servicios.

La realidad resiste el dato estadístico: según un estudio realizado en el Area Metropolitana de San Salvador con menores que trabajan en la calle, éstos conforman un grupo significativo de 100,000 niños cuyas edades van de los 6 años a los 18 años. El promedio se ubica entre los 11 y 12 años. De ellos, únicamente el $42 \%$ nació en San Salvador y el $47.8 \%$ restante procedía de los departamentos afectados por el conflicto. Es significativo que el $6.7 \%$ de los niños no sabían donde habían nacido.

En la mayoría de los casos, los menores se dedican a cuidar carros, limpiar parabrisas y vender periódicos, comestibles, flores, 
lotería y otros artículos. El ingreso mínimo promedio es de poco más de un dolar y medio diario y el máximo, tres dólares. Los menores de la calle están especialmente expuestos a la drogodependencia, sobre todo los inhalantes merecen especial mención, puesto que esta droga es utilizada en forma de pago por los adultos que los explotan". 21

En un estudio de UNICEF citado por Evans y otros, la edad en que los menores empiezan a trabajar se distribuye según el cuadro siguiente. La mayor parte de los menores (59.2\%) trabaja los siete días de la semana y otro $25 \%$ trabaja seis días. Más del $65 \%$ trabaja de 7 a 16 horas diarias y en otro estudio similar una proporción aún mayor de niños trabaja todos los días de la semana durante los 12 meses del año. 22

\begin{tabular}{lcc} 
Edad & Número & Porcentaje \\
\hline $4-6$ & 39 & 13.7 \\
$7-9$ & 95 & 33.5 \\
$10-12$ & 86 & 30.3 \\
$13-15$ & 51 & 18.0 \\
$16-18$ & 13 & 4.5 \\
\hline TOTAL & 284 & 100.0
\end{tabular}

En las familias rurales ubicadas en la extrema pobreza, el niño es desde muy temprana edad un trabajador más, un "instrumento de trabajo", que ha de contribuir a la subsistencia del grupo familiar. A partir de los 4-5 años el niño y la niña comienzan a asumir diversas responsabilidades tanto en el ámbito laboral: trabajo de la tierra (siembra, cosecha, corta, etc.), cuido de los animales, etc., como no laboral: cuido de la casa en ausencia de los padres, cuido de los hermanos pequeños, ciertas compras, acarreo de agua, etc. 23

En definitiva, el niño deja a muy temprana edad de ser niño.

\section{Entorno familiar}

"Los Estados Partes pondrán el máximo empeño en garantizar el reconocimiento del principio de que ambos padres tienen obligaciones comunes en lo que respecta a la crianza y el desarrollo del niño. .. prestarán la asistencia apropiada a los padres y a los 
representantes legales para el desempeño de sus funciones..." (Art.18) "Los Estados Partes tomarán todas las medidas apropiadas para asegurar el pago de la pensión alimenticia por parte de los padres". (Art.27)

5.1. El derecho a recibir los cuidados que necesita de ambos padres y que éstos reciban los apoyos necesarios para cumplir con sus deberes y responsabilidades

En El Salvador, la Constitución establece que la familia es la base fundamental de la sociedad, que gozará de la protección de Estado, que su fundamento legal es el matrimonio y que éste descansa en la igualdad juridica de los cónyuges.

Sin embargo, la desintegración familiar, expresada en la forma de abandono de los hijos y paternidad irresponsable, alcanza un $65 \%$ de los hogares, a lo que hay que añadir condiciones culturales (pérdida de identidad cultural, crisis de valores, violencia intrafamiliar, ...), educativas (analfabetismo), de salud y legislación desfavorables, etc.

Algunos indicadores revelan que en un $62 \%$ de hogares la mujer es jefe (estando la mitad [54\%] de la PEA femenina desempleada y la otra mitad trabajando en el sector informal de la economía); el $43.2 \%$ de los mismos está constituído por uniones de hecho (acompañados) y los nacimientos de menores son ilegítimos en un $69 \% .24$

\subsection{El derecho a la pensión alimenticia}

Según una encuesta realizada en Julio de 1994 a mujeres demandantes de pensión alimenticia por la organización no gubernamental "Mujeres por la Dignidad y la Vida", el proceso para demandar y recibir una cuota alimenticia es complejo, largo y emocionalmente desgastante para las demandantes. Empieza cuando la mujer impone una demanda y se fija una primera cita. Muchos hombres no llegan a los citatorios y en los casos en que no hay lugar donde retener la cuota de forma "administrativa" no existe realmente mecanismo coercitivo que los obligue a comparecer; la "orden de apremio" casi nunca se usa porque los cuerpos de seguridad no la realizan. 
En el caso que comparezca el hombre muchas veces niega la paternidad. Más de un tercio de las encuestadas tuvieron que hacer trámite de reconocimiento de paternidad, con toda la humillación que esto conlleva. Si el hombre sigue negando a sus hijos/as, hay que recurrir al reconocimiento forzoso, un proceso que puede Ilevar años y en la mayoría de casos no se logra, significando esto que la cuota alimenticia nunca se podrá fijar y mucho menos hacer efectiva.

Cuando finalmente se consigue estabecer el monto de la cuota, empieza el martirio del cobro: la mitad de las mujeres tienen atrasos de más de tres meses para recibirla (porque la empresa donde el demandado trabaja no la descuenta o deposita a tiempo, porque el padre trabaja por cuenta propia y no hay modo de obligarlo a que pague, porque el dinero se "extravio" en alguna oficina de la Procuraduría, ...).

A pesar de todo, el número de demandas es cada vez mayor, dado que para la mayoría de las demandantes se trata de ingresos necesarios para la sobrevivencia familiar, por tratarse de mujeres jóvenes (entre 21 y 40 años), con bajos ingresos económicos y nivel de escolaridad, empleadas domésticas o trabajadoras del sector informal, muchas de ellas con más de 60 horas laborales por semana.

Entre los motivos de separación destacan la infidelidad conyugal del marido, la violencia física, psicológica o sexual contra la mujer y el incumplimiento del rol afectivo y proveedor por parte del hombre.

\section{Derecho a trato humanitario y a un proceso judicial respetuo- so de los derechos del niño y humanos}

"Los Estados Partes velarán por que: b) ningún nin̄o sea privado de su libertad ilegal o arbitrariamente. c) Todo niño privado de su libertad tendrá derecho a un pronto acceso a la asistencia jurídica y otra asistencia adecuada, ..."(Art.37) "Los Estados Partes reconocen el derecho de todo niño de quien se alegue que ha infringido las leyes o a quien se acuse o declare culpable ... a ser tratado de manera acorde con el fomento de su sentido de la dignidad y el valor, que fortalezca el respeto del niño por los dere- 
chos humanos y las libertades de terceros ..."(Art.40)

Aunque no tenemos datos sobre el número de niños menores de siete años que se ven sometidos a esta situación, se ha de tener en cuenta que muchos "niños de la calle", entre los que se encuentran también menores de esa edad, tienen frecuentes problemas con las autoridades.

En el Informe sobre Niños y Derechos Humanos de ONUSAL, se concluye que "Muchos niños son capturados por la policía al amparo de "estado de peligro o riesgo" previsto en el Código de Menores. Este es un concepto ambiguo e impreciso que se presta a la arbitrariedad policial, con el agravante de que los menores detenidos por este motivo son conducidos esposados a los Centros de Readaptación, donde quedan depositados sin que tal medida limitativa de su libertad esté sujeta a contralor judicial alguno.

Se ha comprobado que frecuente y sistemáticamente, menores de edad son detenidos por la policía municipal o nacional bajo el cargo de haber incurrido en Faltas de Policía. En estos casos, los niños jamás son puestos a disposición del Juez Tutelar de Menores y deben sufrir las consecuencias de un sistema contravencial que ha sido denunciado por la Misión como arbitrario y violador de derechos humanos fundamentales.

\section{Protección contra abusos, explotación y otras situaciones peli- grosas.}

"Los Estados Partes se comprometen a proteger al niño contra todas las formas de explotación y abuso sexual". (Art.34) "... tomarán todas las medidas... que sean necesarias para impedir el secuestro, la venta o la trata de niños para cualquier fin o en cualquier forma". (Art. .35) "... protegerán al niño contra todas las demás formas de explotación que sean perjudiciales para cualquier aspecto de su bienestar". (Art.36) "... velarán por que: a) ningún niño sea sometido a torturas ni a tratos crueles, inhumanos o degradantes". (Art.37) "... a) velarán porque la adopción sea sólo autorizada por las autoridades competentes... d) adoptarán todas las medidas apropiadas para garantizar que, en el caso de adopción en otro país, la colocación no de lugar a beneficios financieros indebidos". (Art.21) 


\subsection{Protección contra malos tratos, violencia y abusos}

El derecho de los niños a no ser maltratados no es repetado en un porcentaje alarmante. Un estudio que aborda el problema del maltrato infantil en El Salvador (PDDH, 1994), encontró que en el hogar el maltrato físico alcanza un $78.9 \%$, el emocional el $67 \%$, el sexual el $31.2 \%$; y el maltrato por negligencia el $26.7 \%$. Entre los "niños de la calle" la situación es más grave aún ya que éstos son maltratados en el $97 \%$ de los casos.

La misma investigación identificó que el $40 \%$ de los niños nunca tienen la oportunidad de recibir consejos o entablar diálogo con sus padres o con las personas que les cuidan, de modo que se recurre como primera alternativa a algún tipo de maltrato cuando se necesitan tomar medidas educativas o disciplinarias.

En la escuela, el castigo, no necesariamente físico, como medida disciplinaria es utilizado con el $71.4 \%$ de los niños; el maltrato emocional se da con un $56.2 \%$ de los niños, y el maltrato físico es

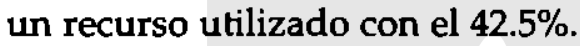

La indagación sobre las causas que llevan a que se maltrate al niño han mostrado que son, en su mayoría, de origen cultural y legal. Entre las principales causas de origen cultural se mencionan: el "derecho" que los padres sienten que tienen sobre sus hijos; la creencia de que el castigo, el golpe y el insulto son las formas disciplinarias más efectivas; la repetición de la acción de maltrato a que los mismos padres y madres se vieron sometidos; la consideración de que con el maltrato contribuye a hacer fuertes a los hijos; y el que los padres y maestros asumen que son sólo sujetos de derecho y no de deberes para con sus hijos.

Entre las causas de índole legal a que se atribuye el maltrato se identificaron: la inexistencia de leyes adecuadas que protejan al niño y la inoperancia de las que existen, lo que permite una conciencia de impunidad por parte del maltratador; la inexistencia de medios adecuados para la denuncia y la falta de una cultura de denuncia; y el poco conocimiento de los derechos del niño. Entre las causas de índole social que también son atribuídas al maltrato figuran: el desempleo, el exceso de trabajo o el tipo de trabajo y la pobreza. 
En esta misma investigación se aplicó un test psicológico (Test de la familia) a niños maltratados y se llevaron a cabo discusiones de grupo con ellos, que permitieron observar que muchos de estos niños lejos de culpar o percibir negativamente la figura del maltratador, se identificaban con él y justificaban la acción. El niño asume e interioriza su culpabilidad y se percibe como merecedor del maltrato. Este fenómeno es realmente preocupante desde una perspectiva psicológica ya que la identificación con el maltratador contribuye a que el niño en el futuro reproduzca la conducta de maltrato. 25

En síntesis se puede decir que los índices de maltrato infantil son alarmantemente altos. En el hogar y la escuela, los dos principales ambientes de socialización del niño, el maltrato, en algún grado y de algún tipo, es una práctica común. Las causas del maltrato no son, como se podría creer por sentido común, derivadas de problemas psiquiátricos anormales por parte de los maltratadores, sino más bien el maltrato es un fenómeno cultural con claras implicaciones sociales y culturales.

\subsection{Protección contra adopciones ilegales y venta}

La Comisión de la Familia, la Mujer y el Niño de la Asamblea Legislativa, conoce en la actualidad de la existencia de "casas de engorde", en donde se mantienen a niños robados que luego son traficados hacia otros países.

La presidenta de dicha Comisión denunció que en el tráfico de menores están involucrados parlamentarios de la anterior legislatura, quienes vendían sus visas a precios altísimos y sacaban del país a muchos niños como sus hijos, mientras que el traficante sobornaba a algún funcionario para conseguir una partida de nacimiento en donde el menor apareciera como hijo del diputado involucrado. También dijo que actuales diputados del Parlamento Centroamericano están envueltos en la misma situación y que se han hecho millonarios con este tipo de prácticas.

Para la Dirección General de Migración y la Policía Nacional Civil el que profesionales y funcionarios se presten a realizar trámites, facilitando documentos fraudulentos a personas que trafican con menores, es algo que está fuera de su alcance. 
El tráfico de menores se agudiza cada vez más. Casos de madres que denuncian el robo de niños en los hospitales como Benjamín Bloom y Maternidad son comunes en la actualidad. También se menciona la existencia de abogados que trafican con menores y convencen a muchas madres de que "les vendan a sus hijos" para llevarlos al extranjero donde vivirán mejor. Además, en muchos casos se señala que el tráfico de menores está relacionado con el tráfico de órganos, aunque nunca se ha podido comprobar esta afirmación. 26

\section{Las practicas educativas}

Temos encontrado distintas maneras de clasificar los progra

1 mas de atención infantil. El problema fue elegir una clasificación adecuada a nuestra realidad, es decir, que no nos obligase a forzar los programas para hacerlos "encajar" en ella, y que al mismo tiempo fuese lo suficientemente amplia y sugerente como para motivar a la reflexión acerca de la diversidad de actores, objetivos, modalidades y actividades que es posible desarrollar en tomo a la atención infantil.

La clasificación adoptada ha sido elaborada por $R$. Myers en su obra "Los doce que sobreviven" , quien en su justificación señala que aunque la interacción con el hogar, la comunidad, las instituciones y los valores culturales ocurre a diferentes distancias del niño, cada uno de estos niveles ambientales influye en el proceso de desarrollo de los primeros años, tanto directamente como mediante acciones y creencias de las personas encargadas de cuidarlo con las que el niño interactúa. Además, es evidente que debe concebirse una estrategia amplia de programación para la atención del nifno y su desarrollo en busca de mejoras reales y duraderas en la supervivencia, el crecimiento y el desarrollo, de manera tal que funcione en todos los niveles. 27

Estas consideraciones propiciaron un conjunto de cinco enfoques a programas complementarios:

1. Atender a los niños en los centros. Se centra en el niroo y busca estimular su desarrollo mediante la satisfacción de sus necesidades inmediatas en centros fuera del hogar.

2. Apoyar y educar a las personas encargadas de cuidar al niflo. Se 
centra en la familia y busca "facultar" a los padres y otros miembros para mejorar su atención e interacción con el niño.

3. Promover el desarrollo de la comunidad. Se centra en la comunidad y busca fortalecer la iniciativa, organización y participación comunitarias en las actividades relacionadas con el niño.

4. Fortalecer los recursos y las capacidades institucionales. Se centra en las instituciones que promueven los enfoques mencionados y busca fortalecerlas mediante el adiestramiento, aporte de materiales, etc.

5. Fortalecer la demanda y la conciencia. Se centra en la producción y diseminación de "conocimientos" para reforzar la conciencia y la demanda.

1. Programas de atención de los niños. (Prestación de un servicio).

\subsection{Centros de acogida de niños.}

Se trata de Centros en los que los niños viven en régimen de internado. En la mayoría de las ocasiones, los menores de 7 años son ingresados a estos Centros por haber quedado huérfanos o haber sido abandonados. Hay también un Centro que acoge a niños maltratados en el hogar mientras los padres o adultos encargados de su atención resuelvan las diferencias que les llevan al maltrato o abandono.

\begin{tabular}{ll}
\hline Institución & Nombre del programa \\
\hline Aldeas Infantiles SOS & Jardines infante SOS \\
CONAMUS & Atención a niños en casa albergue. \\
Socorro Luterano & Hogar Fe y Esperanza \\
\hline
\end{tabular}

Los objetivos de estos Centros suelen ser el ofrecimiento de un ambiente que facilite el desarrollo integral del menor $y$, en algunos casos, la atención psicológica necesaria para el tratamiento de los problemas derivados del abandono, el maltrato o las secuelas del conflicto. 
Atención y desarrollo de la primera infancia. Enfoques y opciones de programas

\begin{tabular}{|c|c|c|c|c|}
\hline $\begin{array}{l}\text { Enfoque de } \\
\text { los programas }\end{array}$ & & Opciones & $\begin{array}{l}\text { Participantes } \\
\text { beneficiarios }\end{array}$ & Objetivos \\
\hline $\begin{array}{l}\text { 1. Atención a los niños } \\
\text { (prestación de un servicio }\end{array}$ & $\begin{array}{l}1.1 . \\
1.2 . \\
1.3 . \\
1.4 . \\
1.5\end{array}$ & $\begin{array}{l}\text { Centros integrados para el } \\
\text { desarrollo del niño } \\
\text { Atención diuma en el hogar } \\
\text { Centros de salud y nutricion } \\
\text { Centros de atención a niños } \\
\text { Establecimientos preescolar }\end{array}$ & $\begin{array}{l}\text {-El niño } \\
(0-2 ; 3-6 ; 0-6) \\
\text {-Embarazadas }\end{array}$ & $\begin{array}{l}\text {-Supervivencia } \\
\text {-Desarrollo amplio } \\
\text {-Socialización } \\
\text {-Rehabilitación } \\
\text {-Atención al nino } \\
\text {-Reducir desigualdades }\end{array}$ \\
\hline $\begin{array}{l}\text { 2. Educación o apoyo a } \\
\text { las personas encargadas } \\
\text { de la atención del niño }\end{array}$ & $\begin{array}{l}2.1 . \\
2.2 . \\
2.3 \\
2.4\end{array}$ & $\begin{array}{l}\text { Visitas al hogar } \\
\text { Educacion/apoyo a padres y } \\
\text { adultos } \\
\text { De niño a nin̄o }\end{array}$ & $\begin{array}{l}\text {-Padres } \\
\text {-Hermanos } \\
\text { mayores } \\
\text {-Familiares } \\
\text {-Futuros padres }\end{array}$ & $\begin{array}{l}\text {-Crear conciencia } \\
\text {-Cambiar actitudes } \\
\text {-Mejorar o cambiar } \\
\text { las practicas } \\
\text {-Reducir desigualdad }\end{array}$ \\
\hline $\begin{array}{l}\text { 3. Promoción del desa- } \\
\text { rrollo de la comunidad }\end{array}$ & $\begin{array}{l}3.1 . \\
3.2 \text {. }\end{array}$ & $\begin{array}{l}\text { Cambio de ambiente } \\
\text { Reforzamiento de la organiza- } \\
\text { ción }\end{array}$ & $\begin{array}{l}\text {-Comunidad } \\
\text {-Llderes } \\
\text {-Promotores } \\
\text {-Miembros }\end{array}$ & $\begin{array}{l}\text { - Crear conciencia } \\
\text {-Movilización para la } \\
\text { acción } \\
\text {-Cambiar condiciones }\end{array}$ \\
\hline $\begin{array}{l}\text { 4. Fortalecimiento de } \\
\text { recursos y capacidades } \\
\text { nacionales. }\end{array}$ & $\begin{array}{l}4.1 \\
4.2 . \\
4.3 . \\
4.4 .\end{array}$ & $\begin{array}{l}\text { Entrenamiento y motivación } \\
\text { Mejoramiento de locales/equi- } \\
\text { pamientos } \\
\text { Ajuste y elevación de la tecno- } \\
\text { logia } \\
\text { Mejoramiento de a organización } \\
\text { y gerencia. }\end{array}$ & $\begin{array}{l}\text {-Encargados de } \\
\text { programas } \\
\text {-Profesionales y } \\
\text { para profesionales }\end{array}$ & $\begin{array}{l}\text {-Crear conciencia. } \\
\text {-Perfeccionar las habilidades } \\
\text {-Aumento de los recursos } \\
\text { materiales. }\end{array}$ \\
\hline $\begin{array}{l}\text { 5. Fortalecimiento de la } \\
\text { demanda y la conciencia }\end{array}$ & $\begin{array}{l}5.1 . \\
5.2 . \\
5.3 .\end{array}$ & $\begin{array}{l}\text { Marketing social } \\
\text { Convocatoria selectiva } \\
\text { Discusion en grupos }\end{array}$ & $\begin{array}{l}\text {-Diseñadores de polfticas } \\
\text {-El público } \\
\text {-Profesionales }\end{array}$ & $\begin{array}{l}\text { - Crear conciencia } \\
\text {-Formar voluntad politica } \\
\text {-Aumentar la demanda } \\
\text {-Cambiar actitudes. }\end{array}$ \\
\hline
\end{tabular}

Elaborado en base a Myers, Robert "Los doce que sobreviven". OPS/OMS/UNICEF, Washington, 1993. 
Entre los problemas de estos Centros se mencionan la vivencia en un mundo artificial, lo que a la larga genera dependencia y miedo a enfrentarse a la realidad y la falta de personal especializado que no permite a los menores superar los traumas con que llegan al Centro.

Como resultados de estos Centros están la respuesta a una'necesidad de protección y seguridad de los menores, la atención en los diferentes ámbitos del desarrollo: salud, higiene, educación, ètc.

\subsection{Centros para el desarrollo del niño de atención diurna}

Esta modalidad de atención a la niñez la integran Centros que en su mayoría tienen el nombre de Centro de Desarrollo Infantil (CDI) y característas muy similares. Se trata de Centros de atención diuma, tipo guardería, para niños pobres de 0 a 6 años, de zonas rurales o urbano marginales.

En estos Centros la atención educativa está orientada a la estimulación temprana y el aprestamiento preescolar y las actividades principales son los juegos, rincones de aprendizaje, salidas de campo, visitas al zoológico y el jardín botánico (los que están ubicados en San Salvador), etc.

Entre los objetivos de estos programas están la atención psicopedagógica y de salud al niño, la preparación para el preescolar o la educación preescolar, la capacitación y apoyo a las madres y educadoras, la organización de directivas de padres de familia, y facilitar la incorporación de las madres a la producción.

\begin{tabular}{ll}
\hline Institución & Nombre del programa \\
\hline CODEFAM & Centro de Desarrollo Infantil \\
COMADRES & Guarderia \\
FE Y ALEGRIA & Centro Infantil de Desarrollo \\
F. SEGUNDO MONTES & $\begin{array}{l}\text { Centro de Desarrollo Infantil } \\
\text { FUNDEMUN }\end{array}$ \\
& $\begin{array}{l}\text { Estimulacion Temprana y Apresto } \\
\text { Infantil }\end{array}$ \\
OFASA & Hogar Escuela Adventista \\
\hline
\end{tabular}

Entre los resultados de estos Centros se mencionan la elevación del nivel nutricional de los niños y su desarrollo saludable, la 
obtención de un nivel de aprendizaje satisfactorio para la incorporación de los niños a la escuela, la realización de programas de organización comunal por medio de las educadoras, y el mayor interés de los padres y las madres por los hijos, su organización en directivas y su participación en las actividades de los centros.

Como problemas se señalan la extrema pobreza de las comunidades, el abandono total o parcial y el maltrato físico y mental de que son objeto los niños por parte de los adultos, la falta de conciencia sobre la necesidad de la educación preescolar, la falta de recursos económicos para el pago de las educadoras y para su capacitación y, en la ciudad, la inadecuada infraestructura de los locales y la inseguridad sobre los mismos, ya que la mayoría son alquilados.

\subsection{Programas de salud o nutrición}

Estos programas abordan aspectos como nutrición, crecimiento y desarrollo, la prevención de Enfermedades diarréicas agudas (EDA's) e Infecciones respiratorias agudas (IRA's), la salud reproductiva, salud perinatal y neonatal, inmunización, salud ambiental, medidas higiénicas, lactancia materna, etc.

Los objetivos de estos programas son la disminución de la mortalidad y morbilidad infantil, mediante la atención y control a las mujeres en edad fértil y embarazadas, atención al parto, vacunación, etc., la capacitación de promotores de salud y la organización de Comités de Salud en la comunidad.

En algunos casos específicos, se busca también la incorporación de los padres (varones) a la tarea de atención de los niños, disminuir la desnutrición infantil o apoyar al Ministerio de Salud para ampliar la cobertura de vacunación.

Entre los problemas más frecuentes mencionados por las instituciones, se suele hacer referencia a la "idiosincrasia" de la población rural que, unido las consecuencias de la extrema pobreza (analfabetismo, carencia de recursos materiales y no materiales, etc.) y la guerra (desconfianza, temor, individualismo, etc.) dificultan el control en la salud de la mujer embarazada y la modificación de los hábitos alimenticios. 


\begin{tabular}{|c|c|}
\hline Institución & Nombre del programa \\
\hline ABES & P. de salud materno-infantil \\
\hline ADEMUSA & P. de salud materna y sobrevivencia infantil \\
\hline ADHU & P. de salud materna y sobrevivencia infantil \\
\hline AGAPE & Hospital nutricional de recuperación infantil \\
\hline ALFALIT & Promoción del crecimiento y desarrollo infantil \\
\hline AMCS & P. de salud materna y sobrevivencia infantil \\
\hline ASADEH & P. de salud materna y sobrevivencia infantil \\
\hline ASALDI & P. de salud materna y sobrevivencia infantil \\
\hline ASPS & P. de salud materna y sobrevivencia infantil \\
\hline CALMA & Programa de salud materno-infantil \\
\hline CARITAS & Programa de salud matemo-infantil \\
\hline CESAD & P. de salud visual y prevención de la ceguera \\
\hline CISI & Control de EDA's y rehidratación oral \\
\hline CISI & Prevención de enfermedades respiratori \\
\hline CISI & Programa de inmunización adquirida \\
\hline DJC & Educación nutricional y estimulación temprana \\
\hline F.KNAPP & Programa de salud materno-infantil \\
\hline FUNDAMAV & Programa de salud materno-infantil \\
\hline FUMA & Programa de salud matemo-infantil \\
\hline FUNDEMUN & Educación de la mujer y supervivencia infantil \\
\hline FUSAL & Programa de salud \\
\hline OPRODE & P. de salud materna y sobrevivencia infantil \\
\hline PLAN DE & \\
\hline PADRINO & Programa de supervivencia infan \\
\hline PROCADES & Salud materna y supervivencia infantil \\
\hline
\end{tabular}

Por otra parte, en opinión de algunas instituciones el programa contribuye al asistencialismo, lo que hace tener dudas sobre la forma en que va seguir el programa cuando el proyecto acabe.

Como resultados más significativos de los programas se citan los diagnósticos de la situación de salud comunitaria, la capacitación de los promotores de salud, la formación de Comités Locales de Salud, la implantación de Centros de Salud Comunitaria, la disminución de IRA's y EDA's, las campañas de vacunación, etc. 


\subsection{Centros de atención a niños en el lugar de trabajo}

La Constitución Política de El Salvador, en su Art. 42, inciso 2, señala que "las Leyes regularán la obligación de los patronos de instalar y mantener salas cunas y lugares de custodia para los niños de los trabajadores".

La Convención para los Derechos del Niño, de la que El Salvador es signatario, señala que "Los Estados partes adoptarán todas las medidas apropiadas para que los niños cuyos padres trabajan tengan derecho a beneficiarse de los servicios e instalaciones de guarda de niños para los que reúnen las condiciones requeridas".28

El Código de Familia modifica este mandato al establecer que "las empresas podrán brindar los servicios señalados [centros de cuidado diario, guarderías infantiles, casas maternales o centros similares] para los menores, hijos de sus trabajadores". Y hace recaer nuevamente en el Estado obligaciones que podrían ser asumidas por los empleadores: “... cuando la incapacidad, insuficiencia económica, ausencias prolongadas o actividades laborales de los padres les impidan asumir la educación inicial del menor, el Estado la proporcionará gratuitamente a través de centros de cuidado diario, guarderías infantiles, casas maternales y otros centros similares." 29

Según el Instituto Salvadoreño de Protección del Menor, entre las empresas e instituciones que estarían planificando $u$ organizando programas de atención al menor mientras los padres trabajan se encuentran: la Fundación Simán, ANTEL, Correos, Hospital B. Bloom, Hospital Militar, Ministerio de Planificación, Banco Cuscatlán, Productos Alimenticios Diana, La Constancia S.A, el Sindicato de Trabajadores del INPEP y la Asociación de Trabajadores de Embotelladora Salvadoreña.

En las encuestas y entrevistas realizadas, esta modalidad de atención infantil está integrada por programas que tienen el nombre de Centro de Desarrollo Infantil (CDI) o Centro de Promoción Infantil (CPI) y característas muy similares a los anteriores.

Institución Nombre del programa

CORTE SUPREMA DE JUSTICLA Centro de Desarrollo Infantil CONAMUS Centro de Promoción Infantil 
Se trata también de Centros tipo guardería, que atienden a niños de 0 a 6 años de miembros de una determinada institución (Corte Suprema de Justicia) o trabajadoras en un lugar determinado (Mercado Central). Su funcionamiento es semejante a los anteriores en la práctica, pero entre sus objetivos también figura también la preocupación por "el bienestar familiar de los empleados de la institución".

Los problemas mencionados tienen relación con la falta de recursos económicos para capacitar a los maestros y la falta de apertura del Ministerio de Educación para facilitar el acceso a su material didáctico.

\subsection{Centros de educación preescolar}

Se trata sobre todo de proporcionar educación preescolar a los niños de entre 4 y 10 años de zonas rurales en las que no hay escuela, generalmente en base a los programas oficiales. Los maestros pueden depender económicamente de la institución o de la comunidad. También se busca la creación de comités de padres para la autosostenibilidad del centro.

\begin{tabular}{ll}
\hline Institución & Nombre del programa \\
\hline DJC & Educación parvularia y básica \\
F. MARCO A. VAZQUEZ & Programa Preescolar Comunitario \\
PLAN DE PADRINOS & Apresto preescolar y ayuda directa \\
U. FRANCISCO GAVIDIA & Atención educativa a la niñez \\
\hline
\end{tabular}

Entre los Objetivos de estos Centros están: incentivar a los padres a que matriculen a los niños en la escuela, facilitar el acceso de los niños a la escuela, e incrementar la cobertura del sistema educativo.

Como resultados principales las instituciones mencionan la mejor integración de los niños a la escuela, la capacitación de los maestros en aspectos de organización comunitaria y formación profesional y, en el caso de DJC, la firma de un convenio con el Ministerio para capacitar a los maestros y validar el resultado del proyecto. 
En cuanto a los problemas, destacan el escaso financiamiento, la alta rotación de los maestros (debida a la poca motivación para el trabajo y al deseo de los maestros de ser "funcionarios"), la escasez de material y la dificultad de obtenerlos del Ministerio de Educación, la deserción de los niños y la poca participación de las comunidades.

\section{Capacitación de padres y educadoras}

$\mathrm{E}$ n este apartado se han incluído programas de capacitación so bre diferentes aspectos: salud, higiene, educación, atención psicológica, etc. dirigidos a los padres y madres de familia o los familiares encargados del cuido de los niños y los educadores/as de guarderías y preescolares

Esta capacitación suele desarrollarse por una institución que actúa como apoyo externo a las comunidades, escuelas o centros de atención infantil, y a la organización que dirige dichos Centros, y tiene dos modalidades básicas: el apoyo y asesoría en la comunidad, escuela o centro de atención infantil, es decir, en el lugar de trabajo, y la capacitación en forma de talleres, charlas, seminarios, etc. fuera del lugar de trabajo.

Los temas a desarrollar, la metodología a utilizar y los ritmos y tiempos de las capacitaciones suelen ser definidos por la institución capacitadora en consulta con los interesados (padres, educadoras, maestros, organismos, etc.) y dependen de las necesidades de los "beneficiarios", del conocimiento que la institución tenga del tema, y de la relación que exista entre ambos.

\begin{tabular}{ll}
\hline Institución & Nombre del programa \\
\hline ACISAM & Programa de estimulación infantil \\
ACISAM & Programa de atención a niños de la calle \\
CIDEP & $\begin{array}{l}\text { Atención comunitaria a la educación maternal y pre- } \\
\text { escolar }\end{array}$ \\
OEFS & $\begin{array}{l}\text { Participación y educación de mujeres en medicina } \\
\text { preventiva }\end{array}$ \\
OMEP & Escuelas de padres de parvularia \\
OMEP & Seminarios de Atención Integral al niño de 0 a 6 años \\
UCA & Proyecto Escuela de padres
\end{tabular}


Los problemas más frecuentemente mencionados por las instituciones son la falta de recursos económicos para mantener o ampliar los programas, la extrema pobreza y el asistencialismo existente en las comunidades, que dificulta la participación activa y responsable de los padres y otros miembros de la comunidad en este tipo de programas, y el nivel académico de padres y personas encargadas de la atención de los niños.

Como resultados de las capacitaciones se mencionan la elevación de la capacidad de los padres y las comunidades en la atención de los niños en diferentes aspectos: salud, educación, higiene, etc. la organización de directivas de padres, clubs de madres jóvenes, etc., la mejora de la estructura y el material de los centros,

\section{Desarrollo comunitario}

\subsection{Mejoramiento del ambiente ecológico y psico-social}

En este apartado hemos incluído los programas orientados a la salud psicosocial o mental en sentido amplio de los niños y la educación ambiental, que van desde la atención a niños de la calle y el tratamiento psicopedagógico de niños de zonas ex-conflictivas, a la educación y organización para la defensa del medio ambiente.

\begin{tabular}{|c|c|}
\hline Institución & Nombre del programa \\
\hline $\begin{array}{l}\text { ACISAM } \\
\text { ASAI } \\
\text { ASPS }\end{array}$ & $\begin{array}{l}\text { Centro de Desarrollo Infantil } \\
\text { Centros de Promoción Infantil } \\
\text { Atención psicológica a niños en zonas ex-con- } \\
\text { flictivas }\end{array}$ \\
\hline A. AUDUBON & Brigadas ecológicas \\
\hline CPAS & Atención psicosocial a jóvenes afectados por guerra \\
\hline PROCADES & Prevención y Atención del Maltrato Infantil \\
\hline FUNVIPRON & $\begin{array}{l}\text { Atención para el desarrollo integral del niño de } \\
\text { la calle y en alto riesgo }\end{array}$ \\
\hline
\end{tabular}

Los objetivos de estos programas suelen ser el acompañamiento, rehabilitación y reintegración socio-familiar de los niños, la atención psicológica y educativa a niños víctimas del conflicto, la detección y tratamiento de trastornos y problemas de salud mental y la capacitación de adultos: promotores, educadores, etc. para 
la atención psicológica, social y educativa del niño. En el caso de la Asociación Audubon se trata de organizar y educar a los niños en la conservación de los recursos naturales.

Entre los problemas que suelen enfrentar estos programas, las instituciones señalan la poca confianza de la gente en este tipo de proyectos, la polarización social y politización de los programas, la no aceptación de los niños en las escuelas por sus características de personalidad, las dificultades en la capacitación de educadoras y promotores por la falta de recursos y el bajo nivel académico, y la falta de experiencia institucional en el trabajo con niños de la calle.

Entre los resultados de estos programas figuran la resolución de algunos de los problemas emocionales de los niños, haber puesto de manifiesto la capacidad de la comunidad para resolver este tipo de problemas, la reintegración de los niños al hogar, etc.

\subsection{Fortalecimiento de la organización}

En este apartado se incluyen programas orientados más al trabajo comunitario y principalmente al fortalecimiento de la organización comunal.

Institución Nombre del programa

ASAPROSAR Estimulación temprana del niño con participación de la familia y la comunidad

OLOF PALME Programa comunitario PROCADES Centros de Desarrollo Infantil

Los objetivos de estos programas suelen estar relacionados con el acompañamiento a las comunidades en la satisfacción de las necesidades de los niños mediante el trabajo directo y la promoción de la organización comunal, el mejoramiento de la calidad de vida del niño a través de acciones promocionales y educativas y la estimulación de la participación de la familia y la comunidad en la atención del niño.

Los problemas más señalados son la escasez de material por la 
falta de fondos, las dificultades que tienen las comunidades para conseguir los recursos y compromisos que se les pide, debido a su situación de extrema pobreza, la poca disposición a participar de la gente, y la deserción de promotores por la falta de estímulos.

Entre sus resultados mencionan: la creación de conciencia en la comunidad sobre la importancia de la atención a la niñez, la capacitación de líderes comunales y el aporte de la comunidad en la atención de los niños, el fortalecimiento de estructuras organizativas a través del apoyo técnico a los Centros de Desarrollo Infantil, la articulación de esfuerzos en el movimienato popular sobre el trabajo con la niñez, y el reconocimiento del trabajo por parte de instituciones gubernamentales e internacionales.

\section{Reforzamiento de la conciencia social}

e trata de programas dirigidos a la promoción de la toma de conciencia sobre la situación del niño, la divulgación, promoción y defensa de sus derechos y la formación de educadores en derechos del niño, y la creación de comités de vigilancia de los derechos de los niños en las comunidades.

Los problemas que enfrentan provienen sobre todo del recelo de la población ante los derechos del niño, ya que su desconocimiento del tema les lleva a pensar que es algo "peligroso", la falta de recursos tanto humanos como económicos y, como consecuencia, la falta de capacidad para cubrir la demanda.

\begin{tabular}{ll}
\hline Institución & Nombre del programa \\
\hline CIDEP & $\begin{array}{l}\text { Promoción de los Derechos Humanos de la } \\
\text { Niñez }\end{array}$ \\
D.N.I. & $\begin{array}{l}\text { Defensa de los Derechos de los Niños } \\
\text { PLAN PADRINOS }\end{array}$ \\
Programa de Derechos del Niño. \\
PROCADES & Programa Tierra de Infancia \\
\hline
\end{tabular}

Entre los resultados destacan la elaboración de materiales y su uso por varias instituciones, haber llegado a los maestros, por la importancia que tienen en la formación del niño y haber capacitado a voluntarios para la vigilancia de los derechos del nifio. 


\section{Conclusiones y recomendaciones}

De lo expuesto se pueden deducir múltiples apreciaciones y conclusiones, sin embargo nuestra pretensión ahora es agruparlas en aspectos centrales. En consecuencia, más que un abanico amplio de conclusiones se ofrece un trabajo de síntesis. En un segundo momento se presentan recomendaciones, entre las que hemos procurado incluir distintas orientaciones: sobre políticas, sobre programas y sobre planes o currículos.

\section{Conclusiones generales}

1. La mayoría de los niños de El Salvador son pobres y la mayoría de los pobres son niños. Nuestros niños nacen y crecen en condiciones de pobreza y extrema pobreza y sin atención apropiada, lo que afecta severamente su presente y su futuro.

En El Salvador la mayoría de los niños menores de siete años no tienen acceso a la educación, buena parte de los menores de cinco años están subalimentados y no reciben atención sanitaria apropiada, muchos no conocen a su papá ni reciben de él ayuda alguna para su sostenimiento, otros están abandonados y/o viven en las calles, donde quedan expuestos a peligros como drogas, prostitución, delincuencia, etc., algunos niños tienen que trabajar para mantenerse y mantener a otros, etc.

En términos generales, las políticas de ajuste económico casan mal con derechos como salud, vivienda, educación, sectores marginados y/o improductivos, etc. Esta situación en la que se desenvuelve nuestra niñez hace que no haya para ellos un sano desarrollo, por lo que tienen serias deficiencias físicas y psíquicas que marcan su presente y su futuro.

Entre esta situación y el ciudadano "consciente, respetuoso, defensor de los derechos humanos, reflexivo, crítico, creador, participativo, protagonista del desarrollo social, capaz de contribuir al sostenimiento del equilibrio ecológico, poseer identidad cultural y capacidades para incorporarse al campo productivo, ser autogestor y preparado para la convivencia social y práctica de los valores éticos; y que se involucre en procesos socializadores, culturales, políticos y económicos, que cumpla con preceptos constitucionales y esté apto para el ejercicio y respeto de los derechos 
humanos", que se describe en la Propuesta de Perfil de egreso del niño y niña de seis años de educación parvularia, existe un largo camino que nos obliga a repensar el tema de la niñez con mayor decisión. (Ministerio de Educación, 1994, p.6)

2. La violencia estructural de nuestra sociedad, producto de la pobreza, la polarización social e ideológica y la guerra, propicia el maltrato infantil del que son víctimas muchos niños salvadoreños.

Si entendemos por maltrato infantil toda acción de abuso físico, sexual, emocional y el abandono, efectuada u omitida, realizada por personas e instituciones, incluído el Estado que, lesionando los derechos del niño, impiden su pleno crecimiento y desarrollo, hemos de concluir que en nuestra sociedad están muy presentes diferentes factores de riesgo.

Junto a las precarias condiciones socio-económicas en que se desenvuelve la vida de muchos niños salvadoreños, que es de por sí un tipo de violencia y factor de riesgo, existe también otro tipo de violencia, generada por el contexto político-militar e ideológico que ha vivido el país que hacen presentes distintos factores de riesgo para el maltrato infantil.

Entre estos factores, podemos señalar diferentes niveles:

A nivel personal de los padres, y sobre todo de los habitantes de las zonas ex-conflictivas, la vivencia de un contexto generalizado de violencia y abandono.

A nivel familiar, la alteración de los roles familiares como consecuencia de muertes, desapariciones, separaciones, duelo, etc.

A nivel social, la guerra trajo consigo el miedo, la desconfianza y el recelo sistemático como forma de relacionarse, la disgregación de la comunidad, etc.

A nivel cultural, destacan el machismo, la consideración del castigo físico como la mejor manera de educar a los hijos, la visión de los niños como "aún no hombres" y la exigencia de una absoluta sumisión a la autoridad paterna, que es en definitiva un modo violento de relacionarse.

Es significativo que la salud mental de la niñez en un país que 
acaba de pasar tantos años de guerra y donde la mayoría de los niños son objeto de maltrato físico y psicológico no se contemple ni en los programas de salud ni en los de educación.

3. La Política Nacional de Atención al Menor representa un paso importante en cuanto que marca objetivos, principios y fundamentos de la atención al menor. Sin embargo, algunas de sus orientaciones estratégicas distan mucho de servir de marco para la identificación de acciones concretas y ubican al Estado en un papel "subsidiario" de la iniciativa privada.

Las Orientaciones Estratégicas contenidas en la Política tienen un muy irregular nivel de concreción, pasándose de definir "el fortalecimiento familiar a través del fortalecimiento económico", lo que "indica que el futuro de los programas de atención a la infancia no puede separarse de conceptos tales como: los acuerdos internacionales y de comercio, las políticas de precios sobre productos básicos, el aumento de los recursos de coordicanión internacional para el desarrollo y el alivio de la deuda externa"; o "Un desarrollo con rostro humano" según el cual "las decisiones de acción estarán dirigidas más por motivos de humanización que económicos"; a la definición concreta de "Líneas de capacitación de recursos humanos", que incluyen "definición del perfil de conocimientos, habilidades y actitudes que deben tener los padres de familia, líderes, etc., construcción de la respuesta de capacitación, desarrollo del proceso de capacitación, evaluación permanente del aprendizaje, etc.".

El principio de subsidiaridad, que en el esquema neoliberal implica la reducción del Estado y la delegación de sus funciones del Estado a la sociedad civil, hace que aspectos fundamentales de la estrategia como son el ya mencionado "fortalecimiento familiar a través del fortalecimiento económico" "la descentralización y desconcentración de los servicios de atención al menor" y el "Rol del sector privado en la aplicación de la política de atención al menor" dejen traslucir, a pesar de la afirmación expresa de que "Esto no debe interpretarse como una descarga de la responsabilidad del Estado", que es precisamente eso lo que se está proponiendo. La atención a la familia y el niño dependen de la buena o mala marcha de la economía nacional (rebalse), del poco o mucho aporte de la cooperación internacional y de la poca o mucha capa- 
cidad de los propios padres y la comunidad para asumir la atención de sus hijos.

4. Una de las mayores debilidades de los programas gubernamentales y no gubernamentales y que cuestiona la propia Política Nacional de Atención al Menor, es su excesiva dependencia de la cooperación económica internacional.

Tanto los grandes programas gubernamentales (PAIN, PROSAMI, EDUCO, etc.) como no gubernamentales de atención al menor dependen directamente de la existencia de recursos de agencias donantes para su funcionamiento, no de la inversión nacional.

En los casos en que no hay esta dependencia directa de fondos externos, los programas se financian a través del Fondo de Inversión Social (FIS), lo que en definitiva es la misma dependencia, aunque indirecta, y viene a contradecir los principios de prioridad de la atención al niño, búsqueda de la integralidad en su desarrollo psico-social y lucha contra el subdesarrollo enunciados en la Política. Los Fondos se han creado para paliar crisis y los efectos de los programas de ajuste y son un mecanismo de compensación social, no para potenciar desarrollo.

La desaparición de PAIN en 1994 por el cese del financiamiento de UNICEF, la finalización del financiamiento de EDUCO en 1994 y su renegociación con el BID, la finalización del financiamiento de SABE y PROSAMI en 1997, generan una permanente incertidumbre sobre los programas de atención al nin̄o.

Frente a esto, la insistencia en la participación comunitaria da la impresión de estarse desembarazando del problema y dejarselo a la gente. $\mathrm{El}$ autofinanciamiento sin financiamiento. El descuido de los deberes constitucionales. El asistencialismo.

5. La orientación mayoritaria de los programas de atención infantil es la preparación de los niños para la escuela, en detrimento de la atención a las necesidades, capacidades y potencialidades propias de la edad.

El desarrollo del niño de 0 a 7 años atraviesa varias etapas con características bien definidas que requieren atención apropiada:

- prenatal; 
- lactante e infante (hasta los 18 meses aproximadamente), que abarca la lactancia y el destete, el aprender a caminar y el desarrollo temprano del lenguaje;

- etapa en la que empieza a caminar y el periodo posterior (aproximadamente de 18 a 48 meses), durante el cual la coordinación, el lenguaje, la habilidad para pensar $y$ las experiencias sociales del niño avanzan a pasos agigantados;

- período preescolar (aproximadamente a los cuatro y cinco años), en el que la coordinación se desarrolla relativamente bien y cuando el desarrollo cognitivo y de habilidades previas a la capacidad de leer y escribir ocurre en forma rápida, junto con una mayor atención en las relaciones con los compañeros; y

- inicio de la escuela, (aproximadamente entre los seis y los ocho años), período de adaptación a la escuela y al mundo circundante; 30

Sin embago, en nuestro país, excepto algunos programas de nutrición infantil y otros dirigidos a adultos, la mayoría de los programas de atención infantil están orientados no tanto a la atención de las características y necesidades propias de cada etapa, cuanto al "aprestamiento escolar". En ello parece influir, entre otras cosas, la identificación del sano desarrollo del niño con su mayor o menor capacidad intelectual (medida en habilidades académicas), y el convencimiento de que el éxito en la escuela garantiza la "mejora de la situación socio-económica". Sin embargo, una parte de estos niños no irá nunca a la escuela, muchos la abandonarán en los primeros grados y sólo unos pocos terminarán la educación básica.

Esto significa, por un lado, que la atención inicial pone el énfasis en la preparación para un sistema que después les excluye, lo que contribuye a generar mayor frustración y al autoconvencimiento de la propia "limitación" y, por otro, que no se atienden adecuadamente sus necesidades del presente.

6. Es necesario una mayor esfuerzo por lograr la "integralidad" de los programas de atención al menor, ya que en la mayoría de ellos se puede observar una tendencia a la desarticulación de los diversos componentes: salud, educación, nutrición, 
capacitación de los adultos, etc.

A pesar de que se conoce y utiliza el discurso sobre la integralidad del crecimiento y desarrollo del niño, los programas de atención suelen estar centrados en uno de los componentes del desarrollo. Los programas de salud y nutrición no incorporan, por ejemplo, actividades de estimulación (de efectos tan positivos en el tratamiento de los niños desnutridos); son relativamente pocos los programas de orientación educativa que incluyen la atención y seguimiento sistemático de la salud del niño; etc.

Otro aspecto de la "integralidad" de los programas de atención infantil es su conexión con otros programas de desarrollo comunitario. Muchas veces se aplica aquí también la teoría del "rebalse" y se da por supuesto que cualquier mejora en la situación de la comunidad revertirá en beneficio de los niños, con ello, no se tienen en cuenta las necesidades del desarrollo psico-social de los niños a la hora de diseñar y planificar programas de desarrollo comunal.

Igualmente, la capacitación de los padres y/o adultos encargados de la atención infantil suele estar enfocada en uno de los componentes: educación o salud o nutrición, aunque estos dos últimos van cada vez más unidos. Sin embargo, en la capacitación de los padres y educadoras sería relativamente sencillo incluir nociones básicas de salud infantil, dietas alimentícias, etc. del mismo modo que en la capacitación de los promotores de salud y padres de familia es posible incluir el conocimiento de las destrezas y comportamientos básicos de cada etapa de desarrollo, actividades de estimulación, etc.

7. Hay una experiencia importante tanto a nivel gubernamental como no gubernamental sobre programas de atención a la niñez y existen intentos de concertación interinstitucional cuyo fortalecimiento favorecería una mayor cantidad y calidad en la atención infantil.

Aunque los actuales procesos de concertación entre los Ministerios de Salud y Educación y las ONG's siguen siendo pobres y marcados por el mútuo recelo $y$, en ocasiones, el enfoque político partidario, existen acercamientos significativos y coincidencias im- 
portantes en cuanto a las prioridades en la atención infantil y los contenidos de los programas, tanto en el área de salud como de educación. Esto proporciona una base sobre la que diseñar futuros planes y programas de acción y posibilita la institucionalización del intercambio.

Hay, además, dos esfuerzos paralelos y hasta el momento totalmente independientes entre sí. Uno para la elaboración de programas y currículos de atención al niño y otro de elaboración de programas y currículos de capacitación a las educadoras. Ha existido ya una primera actividad de acercamiento que abre posibilidades de cooperación en el futuro.

En este punto, es necesario resaltar que el primer papel del Estado democrático es la articulación de la participación en la toma de decisiones políticas y, en este sentido, su función es promover la participación, concertación y articulación de las acciones, no "esperar" a que estas se den. Una decidida voluntad política de dar soluciones a los problemas de la niñez pasa necesariamente por una mayor potenciación de los esfuerzos de la sociedad civil en este campo.

8. Para la mayoría de los programas de atención al menor la participación de la comunidad es más un objetivo, y en ocasiones un problema, que un requisito imprescindible.

Hay distintas formas y grados de participación, pero si como dice la Política Nacional: "la verdadera participación sólo se da cuando quien participa tiene la posibilidad de tomar decisiones", hemos de concluir que la participación comunal en algunos programas de atención infantil no es tan "verdadera". Para las organizaciones que promueven, impulsan y/o ejecutan los programas, la participación de los padres de familia o de los directivos comunales o de los miembros de la comunidad en general es, en la mayoría de los casos, un motivo de preocupación.

Pero esta preocupación no es uniforme. Para unos, se trata de garantizar la conducción comunitaria del programa, es decir, dotar a la comunidad de los recursos y habilidades suficientes para que ellos mismos continúen con la gestión y ejecución del programa. Para otros, se trata de ejecutar un programa entre cuyos com- 
ponentes más difíciles de lograr se encuentra la participación comunitaria. No son pocas las organizaciones que se quejan de la "resistencia y recelo" de las comunidades y sus organizaciones hacia el programa o de que finalizado el mismo la comunidad se olvidó de él, llegando incluso a vender o desmantelar lo construído.

En términos generales, aunque en los distintos programas se procuran tomar medidas que favorezcan la participación de la comunidad, la toma de decisiones centralizada sigue predominando. Incluso la decisión de que la comunidad asuma plenamente el programa no es muchas veces de la comunidad, sino que se le entrega a la misma como parte del "paquete". La participación se considera, desde el punto de vista instrumental, como un medio para hacer los programas más eficaces.

Una definición más completa de la participación de la comunidad en un programa incluye la movilización y el compromiso directo de ésta en todas las fases de la actividad del programa, el diseño, la puesta en práctica y la evaluación. Esto implica la existencia y el aumento de mecanismos organizativos mediante los cuales puede manifestarse la participación; implica también la intervención de la comunidad toda, no sólo de un grupo de individuos seleccionados, en un proceso de discusión y acción sobre una base de continuidad. 31

\section{¿Qué podemos hacer?}

Las tres primeras recomendaciones que presentamos a continuación están basadas en el estudio de R. Myers. Su formulación simplifica e integra diferentes estrategias de acción que son muy adecuadas a nuestra realidad. Hemos añadido también otras que complementan el panorama.

\section{Informar y crear mayor conocimiento sobre el niño utilizando todas las alternativas posibles.}

Es urgente desarrollar un proceso amplio de educación social sobre el niño, sus características, etapas de desarrollo, condiciones que los favorecen o perjudican, etc.

Las acciones que permiten la información y creación de conocimiento pueden ser muy diversas: elaboración de estudios e inves- 
tigaciones y divulgación masiva de sus resultados, realización de campañas de concientización y movilización sobre la niñez, ejecución de planes de capacitación a distancia dirigidos a diferentes agentes relacionados con la atención a los niños, etc.

Estas acciones deben incluir una gama de personas y grupos que enfoque el desarrollo del niño en diferentes niveles y de maneras distintas:

- Los políticos necesitan comprender el problema, las posibles soluciones y las consecuencias de la acción o inacción.

- Los planificadores requieren un mayor conocimiento técnico; deben tener una percepción de las opciones específicas abiertas ante ellos y conocer sobre los costos.

- Los profesionales suelen precisar ayuda para reorientar su pensamiento hacia funciones de mayor supervisión y acciones que se beneficien de su experiencia y preparación académica. Se deberán revisar y analizar los planes de estudio, de manera que los médicos en preparación aprendan sobre salud psicosocial, y los profesores aprendan sobre la salud y nutrición del niño.

- Los que implementan programas (en los gobiernos, organismos no gubemamentales y comunidades) necesitan estar versados en el arte de lo posible, en el pensamiento integral y en las distintas formas de participación real en los programas.

- Las familias y otras personas encargadas de la atención del niño deben llevar a la práctica la información sobre las acciones que pueden emprender en el hogar. Deben saber que son los primeros maestros del niño; necesitan apoyo para saber que lo que hacen es correcto, así como conocimientos sobre lo que deberian hacer y no hacen.

- Los que suministran los fondos nacionales e internacionales necesitan ejemplos que los ayuden a desmitificar los costos y les muestren resultados. Además, deben conocer la interdependencia de la supervivencia y el desarrollo. 32

\section{Establecer una estrategia amplia}

Una estrategia amplia describe cinco enfoque complementarios de programas ya mencionados anteriormente, sugiere una serie de 
directrices de programas y diferencia diversos grupos de edades de niños pequeños que necesitan distintos tratamientos.

\section{Cinco enfoques complementarios:}

Fortalecer la conciencia y la demanda. Este enfoque se concentra en la producción y diseminación del conocimiento y la información. Si no existe comprensión y voluntad políticas, si los planificadores no tienen una visión amplia respaldada por conocimientos y experiencias sólidas, y si la población en general no conoce sus opciones, las acciones continuarán siendo débiles, mal orientadas e ineficaces.

Fortalecer los recursos y las capacidades institucionales. Los esfuerzo para fortalecer las instituciones gubernamentales y no gubernamentales que trabajan para mejorar la atención y el desarrollo de la primera infancia suelen incluir el ajuste de las bases legales, así como el fortalecimiento de los recursos financieros, materiales y humanos para planificar, organizar, poner en práctica y evaluar los programas. Pueden necesitarse nuevas formas de organización para agrupar los diversos esfuerzos institucionales. La capacitación será también una actividad clave.

Impulsar el desarrollo de la comunidad a través del énfasis en el desarrollo de la primera infancia. Este enfoque pone el acento en la iniciativa, la organización y la participación de la comunidad en una serie de actividades interrelacionadas para mejorar el medio físico, el conocimiento y las prácticas de sus miembros y su base organizativa, lo que permite una acción común, y el mejoramiento de esa base para las negociaciones políticas y sociales.

Apoyar y educar a las personas encargadas de la atención del niño. Este enfoque se centra en los miembros de la familia y tiene el propósito de educarlos y otorgarles facultades para que mejoren su atención e interacción con el niño y enriquezcan el ámbito en el que éste se desarrolla, en lugar de buscarle un sustituto. Esta educación y apoyo pueden bridarse a través de visitas, cursos de educación de adultos, a través de medios de comunicación, etc.

Atender a los niños en los centros. Este enfoque directo, que se detiene en el niño, pretende brindar soluciones para el desarrollo saludable fuera del hogar, lo que compensa o enriquece lo que 
ocurre en este. Estos programas pueden adoptar formas tan diversas como una guardería, la atención diuma no institucionalizada, los centros pre-escolares formales y no formales, los grupos de juego, los jardines de infantes y los centros de atención al niño en el trabajo.

\section{Buscar la concertación}

El desarrollo saludable de los niños no es una responsabilidad única de las familias, gobiernos, comunidades u ONG's que constituyen una "sociedad civil". Para hacer mejor uso de los recursos y acumular esfuerzos, se requieren macanismos que faciliten el trabajo conjunto de esas instituciones y de grupos tan diferentes. En el nivel nacional esto puede significar el establecimiento de una gran alianza que moviliza muchos grupos para trabajar juntos por una causa común.

A la larga, el trabajo participativo requiere algo menos glorioso y más dificil que la movilización de muchas personas y organizaciones en una causa común. Significa crear formas duraderas de colaboración en el cantón, la comunidad o la colonia. Para que esto suceda es necesario que ocurran importantes cambios que vayan más allá del simple trabajo conjunto.

Significa establecer condiciones que favorezcan el intercambio de ideas. Significa la participación conjunta en un proyecto o programa que comience con el diagnóstico y la planificación, y que lleve a cabo la implementación y evaluación. Significa reconocer que tienen valor tanto el conocimiento académico como el obtenido por medio de la experiencia. Significa fortalecer la organización local. Significa seleccionar y capacitar al personal profesional y técrico que cree en el trabajo participativo y sabe cómo trabajar en la comunidad.

\section{Sistematizar las experiencias existentes y articularlas para la formulación de la política nacional.}

Debido a las circunstancias socio-políticas por las que ha atravesado nuestro país en los últimos años, se han desarrollado una gran variedad de experiencias educativas de atención al niño en condiciones verdaderamente dificiles. Las condiciones socio-econó- 
micas actuales hacen que la mayor parte de la población, sobre todo la población rural, siga viviendo en condiciones dificiles.

Entre las características relevantes de las experiencias destacan el que la mayoría de ellas se han desarrollado en base a un concepto y vivencia de comunidad muy marcado, han sido planificadas, ejecutadas y evaluadas desde la propia comunidad, realizándose muchas de ellas en momentos en los que la comunidad no contaba con apoyos externos, por lo que se basaban en su propia experiencia, etc.

Rescatar estos y otros elementos positivos de dichas experiencias es de vital importancia en estos momentos en los que, por un lado, el programa de ajuste económico no permite mayor inversión para programas educativos y, por otro, refuerza los procesos de "exclusión social" al dejar a las mayorías pobres sin posibilidades de participación en la dinámica socio-económica.

\section{Recomendaciones sobre el diseño y orientación de los progra-} mas.

El mismo autor nos ofrece una serie de recomendaciones a tener en cuenta a la hora de diseñar y desarrollar los programas de atención infantil. Creemos que su enunciado es lo suficientemente explícito como para no tener que extendernos en otras consideraciones.

- Concentrarse en los niños y las familias cuyas condiciones de vida les ocasionan riesgos de un desarrollo mental, social y emocional retardado o debilitado.

- Adoptar un punto de vista multifacético que logre la integración o convergencia de los programas para sacar partido al sinergismo entre la salud, nutrición y educación.

- Buscar una participación de la comunidad que vaya más allá de las donaciones superficiales hasta la participación real en la planificación, la administración y la evaluación de los programas.

- Ser bastante flexible para respetar y ajustar a diferentes contextos socioculturales; reforzar las formas locales para enfrentar de manera efectiva los problemas de la atención y el desarrollo del 
nin̄o, independientemente de que se introduzcan nuevas ideas.

- Adoptar enfoques o modelos que resulten factibles desde el punto de vista financiero y efectivos en sus costos, aprovechando las tecnologías adecuadas que han probado su eficacia.

- Tratar de llegar al mayor número posible de niños en situación de riesgo.

\section{Recomendaciones sobre el currículo}

- Buscar la integralidad del currículo. Con el objetivo de contrarrestar la tendencia a limitar la programación del desarrollo del niño a un grupo de edades en particular (por ejemplo, al periodo pre-escolar) y para poner el acento en el carácter simultáneo de la supervivencia, el crecimiento y el desarrollo, un marco amplio debe hacer explícita la necesidad de los programas para el desarrollo del niño que abarquen los distintos períodos, teniendo en cuenta las variaciones que ocurren en él.33

- Proporcionar diferentes tratamientos para distintas edades y etapas. Esto significa básicamente que una estrategia amplia debe tener en cuenta las principales diferencias que se relacionan con el proceso de desarrollo del niño, en el que pueden definirse diferentes períodos: prenatal, lactantes, párvulos y pospárvulos, preescolar, y deberán diseñarse distintos tipos de programas para estos diferentes períodos.

- Fomentar la curiosidad infantil. Es decir, saber canalizar la curiosidad por aprender, el interés del niño por el mundo, por el movimiento, es otro de los elementos fundamentales a considerar en un currículo de calidad.

- Prácticar la educación democrática. El ejercicio del arte, del juego, de las dinámicas de grupo son un medio para desenvolver esto en diversas formas: distribución de responsabilidades, elaboración de normas de comportamiento, etc.

\section{Notas}

1. Profesor investigador del Departamento de Educación.

2. Comisión Interinstucional de la Conferencia. Satisfacción de las necesidades 
básicas de aprendizaje: una visión para el decenio de 1990. (Documento de referencia). PNUD, UNESCO, UNICEF, BM. Jomtiem, 1990. Pág. 43

3. Movimiento pedagógico. Calidad de la educación. Lima, 1993. Pág. 15

4. Comisión ... Pág. 9-10

5. Comisión... Pág. 30.

6. Comisión... Pág. 11-12.

7. Comisión... Pág. 6-7.

8. Comisión... Pág.30.

9. Myers, R. Los doce que sobreviven. Fortalecimiento de los programas de desarrollo para la primera infancia en el tercer mundo. Copublicación OPS/ OMS-UNICEF-OREALC. Washington, 1993. Pág. 45.

10. Myers, R. ... Pág. 46-47.

11. UNICEF, Análisis de la situación de la Infancia y de la Mujer en El Salvador. 1991. Pág. 55.

12. UNICEF, ... Pág. .44

13. El Salvador. Proceso, \#626, Septiembre, 6, 1994. Pág. 7-8.

14. Becerra, F., Situación Materno Infantil. En "Análisis del Sector Salud de El Salvador" (ANSAL'94). USAID, OPS/OMS, BM y BID. San Salvador, 1994. Mimeo. Pág. 26.

15. El Salvador. Proceso, \#635, Noviembre, 9, 1994. Pags. 6-8

16. Diario Latino, 10/10/94. Pág. 20.

17. UNICEF, 1991, Pág.16

18. Diario Latino, 12/09/94. Pág. 29.

19. Reimers, F. La formación de recursos humanos. Desafíos y oportunidades. En "La educación en El Salvador de cara al siglo XXI. Desaflos y oportunidades". UCA Editores, San Salvador, 1995. Pág. 15.

20. Fernández, A. El autoritarismo en el aula. En Revista de Psicología de El Salvador, \#32, Abril-Junio 1989. Pág. 167.

21. UNICEF, Análisis de la situación de la Infancia y de la Mujer en El Salvador. 1991.

22. Evans, E. y otros. Educación básica y parvularia. En "La educación en El Salvador de cara al siglo XXI. Desaffos y oportunidades". UCA Editores, San Salvador, 1995. Pág. 229.

23. Pérez, L. Educación y Sociedad rural en El Salvador. Un análisis de la participación popular en los procesos educativos. UNESCO/Alemania. San Salvador, 1994. Pág. 40-41.

24. La Prensa Gráfica, 10/07/94, Pág. 6-B.

25. Fernández, A. (consultor). Diagnóstico Nacional sobre el Maltrato Infantil en El Salvador. Procuraduría para la Defensa de los Derechos Humanos (PDDH), San Salvador, Diciembre de 1994.

26. Diario Latino, 8/12/94, Pág. 8.

27. Myers, R., ...Pág. 106.

28. Convención sobre los Derechos del Niño. Art. 18, inciso 3.

29. Código de Familia. Art. 359, incisos 3 y 5.

30. Myers, R. 1992, Pág. 105.

31. Myers, R. 1992, Pág. 112.

32. Myers, R. 1992, Pág. 558.

33. Myers, R. 1993, Pág. 106. 
Referencias bibliográficas

Aguilar de Guardado, Alba Margarita. Directora Administradora del Centro de Desarrollo Infantil de la Corte Suprema de Justicia. Entrevista inédita. Octubre de 1994.

Asociación Demográfica Saluadoreña (ADS), Encuesta Nacional de Salud Familiar (FESAL'93), San Salvador, 1993.

Becerra, F., Situación Materno Infantil. En Arálisis del Sector Salud de El Salvador (ANSAL'94). USAID, OPS/OMS, BM y BID. San Salvador, 1994. No publicada.

El Salvador. Proceso $N^{\circ} 626$, septiembre, 6, 1994. Págs. 7-8.

El Salvador. Proceso $N^{\circ}$ 635, noviembre, 9, 1994. Págs. 6-8.

Evans, E. y otros. Educación básica y parvularia. En la educación en El Salvador de cara al siglo XXI. Desafíos y oportunidades. UCA Editores, San Salvador, 1995.

Fernández, A. El autoritarismo en el aula. En Revista de Psicología de El Salvador, $\mathrm{N}^{\circ} 32$, abril-junio 1989.

Fernández, A. (consultor). Diagnóstico Nacional sobre el Maltrato en El Salvador. Procuraduría para la Defensa de los Derechos Humanos (PDDH), San Salvador, diciembre de 1994. No publicada.

López, Olinda. Proyecto de Servicio Social: "Atención educativa a la niñez enor de 7 años en áreas rurales y urbano-marginales.

Movimiento pedagógico. Calidad de la educación. Lima, 1993.

Myers, $R$. Los doce que sobreviven. Fortalecimiento de los programas de desarrollo para la primera infancia en el tercer mundo. Copublicación OPS/OMSUNICEF-OREALC. Washington, 1993.

Minislerio de Educación. Propuesta de Perfil de egreso del niño y niña de seis años de educación parvularia. (Versión de trabajo). Nueva San Salvador, 1994.

ONUSAL. Niños y derechos humanos. San Salvador, 1992.

Pérez, L. Educación y sociedad rural en El Salvador. Un estudio de la participación popular en los procesos educativos. UNESCO/Alemania, San Salvador, 1994.

Reimers, $F$. La formación de recursos humanos. Desafíos y oportunidades. En la educación en El Salvador de cara al siglo XXI. Desafíos y oportunidades. UCA Editores, San Savador, 1995.

UNICEF, Análisis de la situación de la infancia y de la maujer en El Salvador, 1991. 